\title{
Estabilidad de los regímenes políticos e inversión extranjera directa, período 1969 al 2008
}

Political regimes stability and foreign direct investment, period 1969 to 2008

Estabilidade dos regimes políticos e investimento estrangeiro direto, período de 1969 a 2008

Andrés David Naranjo Navas

Facultad Latinoamericana de Ciencias Sociales Sede Ecuador adnaranjofl@flacso.edu.ec

https://orcid.org/0000-0002-0835-7544

\begin{abstract}
RESUMEN
El objetivo de esta investigación es determinar los efectos que tiene la inversión extranjera directa (IED) en la estabilidad de los regímenes políticos democráticos y autoritarios. La inversión extranjera directa ha sido estudiada desde varios ángulos, desde la economía y otras pocas desde la ciencia política. Este ensayo es desde la ciencia política, por ello, se trata de llenar ciertos vacíos en la literatura, partiendo con una idea a priori: la tendencia ascendente de la IED conlleva a una mayor estabilidad de los regímenes políticos. Esta investigación establece la estabilidad de los regímenes políticos como variable dependiente, mientras que la inversión extranjera directa se establece como la variable independiente preponderante. Esta investigación se la realizó en 192 países mediante el uso de la metodología análisis de supervivencia (survival analysis). Según los resultados obtenidos, por un lado, el aumento de la IED tiene un efecto positivo en la estabilidad de los regímenes políticos. Por otro lado, las democracias fuertes son las más importantes para atraer la IED, en la que el régimen político de mayor importancia son las democracias parlamentarias.
\end{abstract}

Palabras clave: Estabilidad de los regímenes políticos, inversión extranjera directa, régimen político democrático, régimen político autoritario.

\begin{abstract}
The objective of this research is to determine the effects of foreign direct investment (FDI) on the stability of democratic and authoritarian political regimes. Foreign direct investment has been studied from various angles, from economics and a few others from political science. This essay is from political science; therefore, it tries to fill certain gaps in the literature, starting with an a priori idea: the upward trend of FDI leads to greater stability of political regimes. This research establishes the political regimes stability as the dependent variable, while foreign direct investment is established as the preponderant independent variable. This research was carried out in 192 countries using the survival analysis methodology. According to the results obtained, on one hand, the increase in FDI has a positive effect on the political regimes stability. On the other hand, strong democracies are the most important for attracting FDI, in which the most important political regime is parliamentary democracies.
\end{abstract}

Key words: Political regimes stability, foreign direct investment, democratic political regime, authoritarian political regime.

\section{RESUMO}

O objetivo desta pesquisa é determinar os efeitos do investimento estrangeiro direto (IED) na estabilidade de regimes políticos autoritários e democráticos. O investimento estrangeiro direto tem sido estudado de vários ângulos, da economia e alguns outros da ciência política. Este ensaio é da ciência política, portanto, trata-se de preencher algumas lacunas da literatura, partindo de uma ideia a priori: a tendência de alta do IED leva a uma maior estabilidade dos regimes políticos. Esta pesquisa estabelece a estabilidade dos regimes políticos como a variável dependente, enquanto o investimento estrangeiro direto é estabelecido como a variável independente predominante. Esta pesquisa foi realizada em 192 países usando a metodologia de análise de sobrevivência. De acordo com os resultados obtidos, por um lado, o aumento do IDE tem um efeito positivo na estabilidade dos regimes políticos. Por outro lado, democracias fortes são as mais importantes para atrair IED, em que o regime político mais importante são as democracias parlamentares.

Palavras-chave: Estabilidade de regimes políticos, investimento estrangeiro direto, regime político democrático, regime político autoritário. 


\section{Introducción}

Esta investigación estudia la influencia de la inversión extranjera directa (IED) en la estabilidad de los regímenes políticos. De esta forma, la primera pregunta de investigación es ¿qué impacto tiene la inversión extranjera directa en la estabilidad de los regímenes políticos? Y como segunda pregunta, ¿afecta la inversión extranjera directa de igual forma a la estabilidad de todos los tipos de regímenes políticos? En este sentido, se plantea dos hipótesis, la primera, a mayor inversión extranjera directa, mayor estabilidad de los regímenes políticos, y la segunda, los regímenes políticos democráticos son los regímenes más estables y, por ende, los que mayor influencia tienen de las fluctuaciones de la inversión extranjera directa.

Desde el campo de la economía, existe un amplio análisis académico que surge de considerar como variable independiente la estabilidad de un régimen político, como el democrático y el autoritario. Sin embargo, desde la disciplina de la ciencia política, existe una escasa investigación que considere la estabilidad de un régimen político como variable dependiente. La principal motivación para realizar esta investigación es precisamente llenar este vacío. Por esto, este estudio es fundamental por dos razones. La primera, porque dará un aporte importante a la literatura, al no existir un estudio que busque como la IED puede tener algún impacto en la estabilidad de un régimen político. Segundo, porque este escrito está apoyado en las mediciones del modelo de Przeworski et al. (2000), construido con una base de datos de 135 países, de 1950 a 1990, la cual fue actualizada y optimizada por Cheibub et al. (2010), con una base de datos de 202 países, de 1946 a 2008. El período de investigación de este ensayo es desde 1969 al $2008^{1}$.

\section{Revisión de literatura y marco teórico}

Antes de discutir qué se entiende por estabilidad e inestabilidad de un régimen político, nos referirnos, primero, a la conceptualización de los regímenes políticos. Existen varios autores que nos ayudan en esta tarea, quienes creen que un régimen político es aquel en el que se compone una unidad de análisis (entiéndase ésta por agentes, organizaciones e instituciones), lugar donde se desempeña las políticas económicas, políticas públicas y su interrelación mutua (David Easton, 1999; Jean William Lapierre, 1976; Gabriel Almond, 1956; Samuel Phillips Huntington, 1968; y David Ernest Apter, 1965).

A un régimen político se lo puede dividir en cuatro diferentes elementos. Primero, la sociedad puede organizarse a través de diversas instituciones para expresar sus demandas. Segundo, está compuesto de instituciones que representan los diferentes poderes políticos, las reglas de interacción entre ellas y la sociedad. Tercero, el entendimiento de la actividad política a través de los diferentes valores de la sociedad. Por último, un régimen político se encuentra inmerso en el entramando internacional. La comunidad internacional también ejerce presión sobre la estabilidad de los regímenes políticos, sean estas compresiones diplomáticas o bélicas.

Existen algunos autores que han analizado los regímenes democráticos, como Nun (2002), Held (2001), Bobbio (1985), Linz (1998), O’Donnell (2010), Przeworski (1995), Plotke (1997), entre otros.

\footnotetext{
${ }^{1}$ No se ha procedido a completar la base de datos hasta años más recientes porque ello involucraría un trabajo de campo muy extenso, con la complejidad del acceso a información primaria de cada caso de estudio, y el uso adecuado de metodologías similares a las utilizadas por Cheibub et al. (2010).
}

Sapienza: International Journal of Interdisciplinary Studies | Vol. 2 | n. 1 | jan - mar | 2021 | e-ISSN: 2675-9780 
Estos autores entienden un sistema político democrático como una construcción alrededor de cuatro principios indispensables: estado de derecho, derechos humanos, elecciones libres, división de poderes. Cada uno de estos elementos ha sido estudiado de forma exhaustiva, y sin embargo todos están conectados a una idea central: la representación pública. Lo opuesto a la representación es la no participación, la exclusión, y lo opuesta a la participación es la abstención (Plotke, 1997).

Por otro lado, los sistemas políticos autoritarios también han sido investigados por algunos autores como Huntington (1998), Collier (1985), Collier y Levitsky (1998), Gandhi (2008), entre otros. Los sistemas políticos autoritarios se construyen alrededor de ideas opuestas a la participación o inclusión (Naranjo N. 2017, 3). La exclusión conlleva a la alteración del estado de derecho, la débil protección a los derechos humanos, elecciones arregladas o eliminadas, y el apoderamiento de las otras funciones del estado. Es evidente, sin embargo, que muchos regímenes autoritarios gobiernan haciendo uso de las instituciones democráticas, las cuales se construyen en una fachada disimuladora (Gandhi, 2008).

El objetivo principal de la investigación es analizar la influencia que tiene la inversión extranjera directa en la estabilidad de los regímenes políticos, razón por la cual, y en referencia a la estabilidad de un régimen político, se enfocará en las definiciones descrita por Saravia (2015) y en el diccionario de Bobbio, Matteucci y Pasquino, quienes particularizan "a la estabilidad diciendo que es la previsible capacidad del sistema de durar en el tiempo" (Garzón Valdes, 1992); y en la de Marshall y Jaggers (2009), quienes consideran que la durabilidad del régimen político representa el número de años desde el cambio de régimen más reciente. En este sentido, estos autores midieron el número de años hasta que cambia de régimen político entre democracias y autocracias. Para esto, realizaron un análisis en 189 desde el año 1800 al 2009.

Lawrence (2007) considera como estabilidad política los regímenes institucionales que pueden abarcar múltiples gobiernos. En este sentido, Lawrence menciona un ejemplo clásico, el de Estados Unidos, el cual se ha formado como un régimen continuo desde 1789, aunque ese régimen ha abarcado múltiples gobiernos y ha sobrevivido a la guerra civil y a la invasión. Sin embargo, esta estabilidad se rompe cuando un nuevo régimen surge a través de un golpe de estado, o un cambio significativo en el sistema constitucional del Estado. Asimismo, Saravia (2015) considera que la estabilidad del régimen político debe ser medida por el número de años en que se ha establecido un régimen político particular.

De acuerdo a Asteriuo y Price (2000), a la variable inestabilidad política se la puede entender de diversas maneras. Así existen algunos autores que dan sus diferentes puntos de vista de los que entienden por inestabilidad de un régimen político, entre ellos está Ake y Sanders (Ake, 1974; Sanders, 1981). Ake la define como la regularidad de aquellos cambios que evidencian un desafío o reto respecto al orden normalmente establecido. La regularidad de los cambios que evidencia un desafío o reto al orden normal se diferencia de los ciclos normales de los regímenes políticos porque los retos definidos por Ake pueden llegar al cambio de régimen político, mientras que los ciclos normales son contrarrestados por una serie de políticas públicas.

Sanders conjura la estabilidad política con la normalidad institucional, y la inestabilidad política cuando el régimen, gobierno o comunidad los objetivos no son alcanzados y no cumplen los compromisos. Por otro lado, Ake critica la postura que argumenta que la modernización produce inestabilidad política: mientras la economía mejora, se crea nuevos grupos que quedan relegados, quienes se convierten en los demandantes de los regímenes políticos. Ake responde que algunas formas de participación política apoyan los regímenes políticos lo que resulta en una mayor estabilidad. Sanders y Ake exponen diferentes formas de medir el grado de inestabilidad política. El modelo de Sander se basa en la revisión experimental de casos de estudio, mientras que el modelo de Ake se basa en la revisión teórica de la argumentación sobre la inestabilidad política. 
Cukierman, Edwards, y Tabellini (1989) proponen que los países con mayor inestabilidad y polarización política, mayor es la ineficiencia en el equilibrio de la estructura fiscal, en el sentido de que la recaudación fiscal es más costosa que su adminsitración. Por otro lado, autores como Edwards y Tabellini (1991), Chen y Feng (2000), Feng (1997) y Alesina et al. (1992), han utilizado varios modelos que pronostican la probabilidad de que exista cambios de gobierno. Estos cambios pueden ser utilizados como un proxy de la inestabilidad política. Así se puede ver que se utiliza aproximaciones desde el cambio de gobierno de acuerdo a las percepciones del gobierno actual, como por ejemplo los golpes de estado y las transferencias de gobierno.

Por otro lado, Jong-A-Pin (2008) midió la inestabilidad política a través de un análisis factorial exploratorio, sugiriendo que tal vez no es la mejor manera de apreciar un indicador de inestabilidad política. No obstante, pudo distinguir y dividir en cuatro diferentes tipos de inestabilidad política, como, primero la inestabilidad de un régimen político, segundo la inestabilidad dentro de un régimen político, tercero, la violencia que es motivada por las masas, y, por último, la violencia que es motivada políticamente.

Existen investigaciones sobre la durabilidad de un régimen político. La durabilidad de un régimen político se mide en número de años totales antes de cambiar a un nuevo régimen. Así se tiene, por ejemplo, las de Knutsen y Nygard (2015), quienes analizan las causas por las que las democracias y las dictaduras son más duraderas que las semidemocracias. Knutsen y Nygard mencionan tres causas plausibles. Primero, que las semidemocracias emergen bajo condiciones de inestabilidad política. Segundo, son otras características de los regímenes políticos las que explican la durabilidad. Tercero, las medidas políticas tomadas en las democracias existentes no registran todos los cambios dentro de estos regímenes. Para este análisis se utilizaron los modelos de supervivencia. Concluyen que, aunque algunas semi democracias duran más que otras, generalmente son mucho menos duraderas que las democracias y las autocracias. Las semi democracias son regímenes políticos particularmente inestables, esto se debe a la composición institucional de tales regímenes que causa una durabilidad reducida. Sin embargo, las semi democracias no tienen más probabilidades de experimentar cambios de régimen liberalizadores que las autocracias.

Algunos autores han tenido la incógnita sobre qué hace que los regímenes políticos perduren. Przeworski y Limongi (1997) trataron de responder a esta inquietud a través del rápido crecimiento económico en referencia a las democracias, al estudiar 224 regímenes, de los cuales 101 eran democráticos y 123 autoritarios entre los años 1950 y 1990. Przeworski y Limongi plantearon que pueden existir dos explicaciones. La primera, es desde la perspectiva endógena, es decir que las democracias surjan a medida que los países se desarrollan económicamente. Y la segunda, es desde el punto de vista exógeno, en la que las democracias pueden establecerse independientemente del crecimiento económico. Estos autores concluyen que el surgimiento del régimen democrático no es un subproducto del desarrollo económico. Sin embargo, autores como Huntington (1968) y O’Donnell (1979) creen que el desarrollo económico sí influye en la sobrevivencia del régimen democrático y autoritario. Huntington sostuvo que los regímenes políticos democráticos y autoritarios pueden ser más inestables cuando un país se somete a la modernización. En cambio, O’Donnell menciona que los regímenes políticos democráticos pueden morir cuando un país agota la etapa fácil de la sustitución de importaciones. Según Moran (2000), y desde la perspectiva de la inversión extranjera directa, ésta si puede afectar en la estabilidad de los regímenes políticos.

De esta forma, la literatura muestra un debate sobre la teoría de la modernización. Por un lado, Huntington (1968), al analizar las razones que produjo un debilitamiento de la autoridad y de la legitimidad del gobierno en América Latina, Asia y África, menciona que fue producto de un cambio social, de una rápida movilización de nuevos grupos y de un lento desarrollo de las instituciones políticas. En este sentido, Huntington menciona que son dos objetos diferentes el crecimiento 
económico y la estabilidad política. Esto debido a que, en algunas situaciones, el crecimiento económico si puede promover la estabilidad política, pero en otros casos el crecimiento económico puede socavar dicha estabilidad política. Por otro lado, Hannan y Carroll (1979) realizaron un estudio de algunas hipótesis desde la teoría de la modernización en referencia a las causas de los cambios en la estructura política nacional. Los resultados obtenidos fueron que el producto nacional bruto per cápita, la población y la diversidad étnica si afectan a las tasas generales de cambio político. Para esto analizaron 90 países, mediante el método de historia de eventos, desde el año 1950 a 1975.

Según Londregan y Poole (1990), el crecimiento económico sí puede tener un impacto en la supervivencia política de los gobernantes. Señalando la alta correlación entre el ingreso y la estabilidad de los regímenes políticos, algunos defensores de la teoría de la modernización, como por ejemplo Boix y Stokes (2003) y Lipset (1959), afirman que el crecimiento económico si tiene un impacto causal sobre la probabilidad de transiciones de dictadura a democracias. Por otro lado, de acuerdo a Gandhi (2008), en las dictaduras, un mayor crecimiento económico puede producir dictaduras más institucionalizadas.

Al tratar de ver las discusiones entre la estabilidad de los regímenes políticos en referencia a otras variables, podemos decir que ésta investigación se basa en la teoría de la modernización (Przeworski \& Limongi, Modernization: Theories and Facts, 1997), en la que a medida exista un crecimiento la economía, en este caso la inversión extranjera directa, se desarrolla los regímenes políticos.

\section{a. Estabilidad del Régimen político}

Existe una muy escasa literatura en la que tome como variable dependiente la estabilidad de un régimen político. Entre esas está el estudio de Mutascu (2009) de Rumania, quien toma como variable dependiente la durabilidad del régimen político y como variables independientes el crecimiento económico y la forma de gobierno. Este artículo, que cubre el período de 1926 a 2007, se basó en el "Modelo Probit lineal". Así, Mutascu demostró que la longevidad de un sistema democrático es fuerte mientras el crecimiento económico es alto.

Desde la teoría de la modernización, se puede encontrar estudios realizados por algunos autores, quienes analizan como la estabilidad de un régimen político puede estar influenciada ya sea por el crecimiento económico, el costo de capital del usuario, salarios reales, las diferentes escalas de producción y los varios indicadores de incertidumbre económicos (Moran, 2000; Boix y Stokes, 2003; Lipset, 1959; Gandhi, 2008; Chen, 2007; Londregan y Poole, 1990; Alesina y Perotti, 1992; Mutascu, 2009; Przeworski, 1991; Diamons, 1988; Fielding, 2002; Brady, 2016). De acuerdo a este estado del arte, es por esta razón que esta investigación plantea utilizar otras variables independientes que sea de control. Estas variables de control son el crecimiento económico (PIB per cápita), salarios reales, desempleo, desigualdad y el estado de derecho. El estudio comienza proponiendo, a priori, que cada una influye en la variable dependiente de forma simultánea, y que ninguna de ellas se la puede considerar como variables intervinientes.

\section{b. Inversión extranjera directa}

Al revisar las investigaciones de Mayhew (1996), Guerra (2001), Busse y Hefeker (2005), Azzimonti y Sarte (2007), Jense (2008), entre otros, parece ser clara la conexión entre la inversión extranjera directa y la estabilidad de un régimen político. Sin embargo, las investigaciones que estos 
autores han realizado han planteado la influencia de la estabilidad de los regímenes políticos en la inversión extranjera directa.

Existen pocos trabajos que presenten la inversión extranjera directa como la variable independiente, y la estabilidad de un régimen político como variable dependiente. Entre esos tenemos el libro de Theodore Moran (2000), el cual indica una causalidad de la siguiente forma: un gobierno aplica políticas públicas y económicas para que la inversión extranjera directa aumente o disminuya y que ésta ayude o perjudique la estabilidad del régimen político. Un ejemplo de esto es la gráfica que muestra en la página 3 de la primera parte, en la que se puede visualizar los 10 países más importantes con relación a los niveles de la IED en países en vía de desarrollo. En dicha gráfica se constata que, de 1991 a 1997, la IED es de alrededor de mil millones de dólares en 1991, y 37 mil millones de dólares en 1997. Con esto se puede llegar a una conclusión preliminar: las aportaciones de Chen (2007), Londregan y Poole (1990) y Alesiana y Perotti (1992), demuestran empíricamente la influencia que tiene el crecimiento económico sobre la inestabilidad de un régimen político. En este sentido, la inversión extranjera directa sí puede tener efectos en la estabilidad de un régimen político ya que es un importante flujo económico.

Según Demirhan y Masca (2008), los gobiernos participan en una competencia política cambiando los factores clave de sus políticas económicas, tales como las condiciones del mercado laboral nacional, los impuestos sobre las sociedades, las barreras arancelarias, los subsidios, las políticas de privatización y regulación para mejorar la actividad de la IED en sus países.

Finalmente, Sachs y Warner (1995) han demostrado que los países pobres en comparación con los ricos tienen mayores tasas de crecimiento si se abren al mercado mundial. No obstante, ¿qué tan riesgoso es abrir sus mercados hacia la inestabilidad de un régimen político? Autores como Bussmann, Scheuthle y Schneider (2006) han indicado que no hay evidencia empírica que revele que un país obtenga mayores riesgos de inestabilidad política si se abren.

\section{c. Crecimiento económico}

Varios indicadores se emplean para medir el nivel de inestabilidad de un régimen político, entre esos están los indicadores de gobernabilidad del Banco Mundial (Banco Mundial, s.f.), el cual es utilizado con fines académicos. Estos indicadores son empleados en estudios empíricos y tienden a ser de dos tipos. Por una parte, desde el campo de la economía, la inestabilidad política es la variable independiente, a la cual se la relaciona con varias variables dependientes como la inversión y el crecimiento económico. Por otra parte, desde la disciplina de ciencia política, la inestabilidad política se convierte en la variable dependiente (Cajal, s.f.)

Este artículo se basa desde la disciplina de la ciencia política, así se tiene que de acuerdo a Lipset (1959), el crecimiento económico asegura la democratización. Por otro lado, Diamond (1988, 3) cree que la durabilidad de un régimen político varía con el rendimiento económico. Diamond considera, también, que las dictaduras son más capaces de canalizar los recursos hacia la acumulación y que las democracias son más vulnerables a los retrocesos en el desarrollo económico. Siguiendo esta línea, tenemos además a Almond (1991), quien muestra estadísticamente que el crecimiento económico genera un aumento de democratización del estado. Asimismo, Przeworski $(1991,32)$ alude a que el crecimiento económico promueve la estabilidad política.

La inestabilidad de un régimen político puede ser producida por varios elementos, entre ellos están los conflictos entre partidos políticos rivales, recursos económicos o la simple cercanía geográfica a naciones en conflicto. La literatura ha reportado las conexiones que existen entre el crecimiento 
económico y la estabilidad de un régimen político. Así tenemos los estudios cuantitativos transversalesnacionales y los estudios históricos-comparativos. Entre estos está la ecuación optimista de Lipset (1979), que posteriormente fue reformulada por Diamond (1992), en la que cuando mejor le va a la gente de una nación, en promedio, mayores son las oportunidades de que favorezcan y mantengan un sistema democrático. No obstante, según Przeworski y Limongi (1997), no existe un determinado nivel de crecimiento económico que sea determinante de la democracia.

Sin embargo, ¿qué régimen político es más estable con el crecimiento económico? Chen (2007) demuestra empíricamente que los estados con un alto crecimiento son las democracias fuertes. De esta forma, Londregan y Poole (1990) y Alesina y Perotti (1992) también muestran la probabilidad de que la tasa de crecimiento económico influya en forma positiva en la estabilidad política. Empero, Robinson (2006), al analizar estos efectos, llega a la conclusión de que el crecimiento económico no muestra un efecto causal sobre las democracias. Así también Campos y Nugent (2002) no encuentran una relación causal entre el crecimiento económico y la inestabilidad política. Por lo tanto, se puede decir que las investigaciones sobre la relación causal entre la estabilidad de un régimen político y el crecimiento económico no son concluyentes.

\section{d. Salarios reales}

Escasa literatura exhibe una relación entre salarios reales y estabilidad de un régimen político, entre esas está el trabajo de Fielding (2002). Fielding presentó un modelo de series temporales en Sudáfrica de 1960 a 1992 para ver el efecto que tenía el stock de capital agregado en el sector manufacturero explicado por el costo de capital del usuario, salarios reales, la escala de producción y varios indicadores de incertidumbre económica sobre la inestabilidad política, derechos políticos y derechos de propiedad civil. Fielding sugirió que estas variables pueden explicar algunas de las variaciones en el rendimiento económico sudafricano a lo largo del tiempo, pero que las variaciones entre países en las medidas de capacidad son difíciles de vincular directamente a los cambios de políticas públicas.

En uno de los artículos de Brady (2016), se puede observar la correlación existente entre el aumento de la inestabilidad de un régimen político y el empeoramiento del desempeño económico. Brady argumenta que dicha inestabilidad puede ser producida por la caída en la participación del empleo industrial o manufacturero porque los inversionistas prefieren la mano de obra más barata. Aunque para Tomaselli y García (2000) es más importante la disponibilidad de mano de obra capacitada y estable, ya que puede contribuir a un mayor crecimiento y recibe retornos conmensurables (Tomaselli \& García, 2000).

La mano de obra capacitada es un factor inductor a la atracción de inversión, especialmente cuando se trata de empresas que involucran la adopción de tecnologías nuevas (Tomaselli \& García, 2000). El surgimiento de los diferentes tipos de tecnologías ha dado un impulso en la capacidad de las compañías para gestionar eficientemente diversas cadenas de aprovisionamiento a nivel mundial con diversas fuentes y el aprovechamiento de la integración económica mundial.

Según Spence y Brady (2016), las democracias occidentales han experimentado un rápido aumento de la inestabilidad política producidas por varios factores, entre ellas la tecnología. La participación de las manufacturas en el empleo decayó del 40\% en 1960 a $20 \%$ en el 2016. Las tecnologías han impulsado la polarización del empleo y del ingreso, produciendo una baja en la participación de los empleos quienes tienen ingresos medios y un aumento en los de ingresos altos y bajos. 
A pesar de que hay escasos estudios que relacionen la evolución de los salarios reales con la estabilidad de un régimen político, esta investigación parte del supuesto de que una tendencia ascendente de los salarios reales ayuda a mantener estable los regímenes políticos, sean estos autoritarios o democráticos.

\section{e. Desempleo y desigualdad}

La variación de la inversión extranjera directa puede generar empleo o desempleo. Esto puede afectar gravemente el crecimiento económico y por ende la estabilidad de un régimen político (Brady, 2016). El desempleo puede generar desigualdad y, por consiguiente, inestabilidad y la fragmentación de un régimen político. El desempleo y la desigualdad pueden socavar la capacidad de los funcionarios para implementar políticas económicas eficaces.

Según Przeworski, las democracias pueden durar más a medida que aumenta su ingreso per cápita. El ingreso per cápita puede variar de acuerdo a la inversión extranjera directa. Los países que "incursionan en las vías democráticas cuando su nivel de ingresos es más bajo tienden a sufrir una mayor inestabilidad" (Przeworski A. , 2011, pág. 2). Tomaselli y García (2000) mencionan que es fundamental para un país ser políticamente estable y transmitir esa imagen al resto del mundo, ya que para un inversionista es importante tener un mínimo de seguridad en cuanto a la estabilidad de un régimen político del país donde va a invertir, para que de esta forma "los factores extra sectoriales no afecten la rentabilidad del negocio. Un clima de inestabilidad política puede perjudicar la capacidad de una región o país para atraer inversiones" (Tomaselli \& García, 2000). A medida que la estabilidad de un régimen político es mayor, menor será el riesgo para el inversionista.

\section{f. Estado de derecho}

El Estado de Derecho es un modelo de un país por la cual se rige por un sistema de leyes descritas e instituciones en torno a una constitución. La constitución es el fundamento jurídico de las autoridades y de funcionarios. Con esto, toda autoridad del Estado está limitada por el marco jurídico. Consecuentemente, toda acción o medida debe estar sujeta a una norma jurídica previamente aprobada. Existe un amplio debate del origen del Estado de derecho. Así algunos consideran que nace en una de las obras de Immanuel Kant (1972), (2005), otros en una de las obras de Robert von Mohl (1832-1834), y finalmente, algunos lo adjudican a la doctrina alemana del Rechtsstaat Gazzi (2007), White (2006), Alliende (1998).

Todas las definiciones del Estado de derecho, así también del imperio de la ley, tienen un núcleo común, "la idea de que el sistema legal es un sistema jerárquico (usualmente compuesto por normas constitucionales) que aspira a la completitud, aunque nunca la alcanza por completo" (O'Donnell G. , 2002, pág. 13).

Por otro lado, existen autores que también han analizado el Estado de derecho en la calidad de la democracia. Así tenemos a Lipset (1996), Linz y Stepan (1996), Molina y Levine (2007), PNUD (2004) Diamon y Morlino (Ed), O’Donnell, entre otros. El Estado de derecho hace referencia a que "todos los ciudadanos son iguales ante la ley, existen leyes claras, públicamente conocidas, universales, estables, justas y coherentes aplicadas por un poder judicial independiente" (Diamond \& Morlino, Introduction, pág. X). Por otra parte, O’Donnell en cambio menciona que la base de toda dimensión en 
referencia a las instituciones de la calidad de la democracia se basa en el Estado de derecho (citado a O’Donnell, PG XIV).

Las organizaciones estatales o gubernativas pueden ser de dos tipos, el Estado autocrático y los Estados de derechos. En los Estados autocráticos gobierna una sola persona, quien no responde de sus actos a alguna otra autoridad. En los Estados de derechos, toda persona, incluida la autoridad máxima, están sujetos por las normas y leyes. Los Estados de derechos se caracterizan por ser democracias participativas. Sin embargo, no todo Estado de derecho posee organización democrática. La razón de esto es porque la única condición es el código de leyes y no la participación ciudadana.

El Estado de derecho puede tener dos significados. La primera es la acepción débil y la segunda la acepción fuerte. La acepción débil o formal puede ser en Estados democráticos y autoritarios. Esta acepción tiene el requisito de que en su organización político-social deba ser concedido por la ley y practicado de acuerdo a las formas y procedimientos que están establecidos en el mismo. En la acepción fuerte o substantiva, en sentido real o material Raz (1985), todo poder debe estar limitado por la ley, "que condiciona no solo sus formas sino también sus contenidos" (Ferrajoli, 1989, pág. 896).

Para las dos diferentes acepciones se necesita cumplir con alguna de los cinco requisitos descritos a continuación. La acepción débil o formal debe cumplir cuatro, mientras que la quinta exigencia es característica de la acepción fuerte o substantiva. El primero, un Estado debe crear órganos diferentes. Cada órgano cumplirá una de las funciones del Estado. Segundo, los órganos de poder deben ser autónomos. Tercero, se debe establecer la forma de nombramiento a los titulares, solemnidades y procedimientos de cada cargo en los diferentes órganos. Cuarto, se debe institucionalizar el poder en instituciones jurídicas políticas. Quinto, se debe respetar, promover y consagrar los derechos esenciales que emanan de la naturaleza de las personas.

Las democracias occidentales se basan en ideas claras como la aceptación de la protección de los derechos humanos, el intento de disminución de la pobreza, eliminación de la segregación racial, de la desigualdad sexual, y la protección de las libertades de culto. La negación de estos parámetros conformaría la idea de un sistema jurídico no democrático. La aceptación de estos principios conformaría la idea del Estado de derecho (Raz, 1985, pág. 264).

Por otro lado, autores como Reyes Heroles (Meyer, 1995) consideran que el Estado de derecho tiene cuatro principios. Así tenemos el principio de legalidad, la obligatoriedad del derecho con respecto al Estado, la supremacía de la constitución, y finalmente la responsabilidad del Estado por sus actos frente a los ciudadanos. El estado de derecho es importante para la estabilidad de un gobierno democrático, es decir, un estado de derecho débil influye en la estabilidad de los regímenes democráticos (Linz y Stepan 1996). Además, un estado de derecho estable "permite la evaluación racional de los riesgos de los negocios, la reducción de los costos de transacción y de la arbitrariedad gubernamental” (Lipset S. , 1996, pág. 76). Así vemos en la estabilidad del estado de derecho tiene una relación directa con la estabilidad de los regímenes políticos.

Autores como Molina y Levine (2007) no incluyen el Estado de derecho como una dimensión de la calidad de la democracia. Sin embargo, al revisar la literatura vemos que Diamond, Morlino y O’Donnell sí utilizan el Estado de derecho en sus mediciones. Así, queda claro que una sociedad que presente una fuerte estabilidad "del principio del Estado de derecho, mayor será la calidad de la democracia y mejor será la sociedad” (Linz \& Stepan, 1996, pág. 36).

\section{III.Metodología: Análisis de Supervivencia (Survival Analysis)}


Para poder responder las preguntas de investigación se procederá a la utilización de la metodología "análisis de supervivencia", en inglés, "survival analysis". Este es un modelo de regresión y correlación en referencia al análisis de tiempo de seguimiento para cada unidad de observación hasta el momento que ocurre un evento predefinido (Salinas, 2008, pág. 75). Con este propósito, se estudiará todos los países, desde el año 1969 al 2008. Se analizará el impacto que tienen las variables independientes, siendo de interés para este estudio la inversión extranjera directa, a fin de observar la influencia que tienen en la variable dependiente, es decir en la estabilidad de los regímenes políticos.

Este método está inmerso en el tiempo. En términos estadísticos, "se podría acotar a la cantidad de tiempo que una unidad experimental contribuye en un estudio, hasta la aparición de un evento definido con anterioridad. En los primeros análisis de sobrevivencia, se consideró la muerte como la variable de desenlace (evento) de interés, pero en realidad se puede tomar como evento cualquier variable que defina el investigador” (López, Martínez, \& Moreno, 2014, pág. capítulo 34).

El análisis de supervivencia (survival analysis) es un método utilizado comúnmente en estudios clínicos, ingeniería y economía (Fuentelsaz, Gomez y Polo, 2004; Lin, 2014; Cox, 1972; Santabárbara, 2016), empero existen pocos trabajos que lo han empleado en ciencia sociales, más específicamente en la ciencia política (Allison, 2014; González-Bustamante y Olivares, 2016; Martínez, 2015). Desde esta perspectiva, una de las ventajas de utilizar esta metodología en la ciencia política y la política comparada es, por un lado, el conjunto de técnicas que están diseñadas para predecir el tiempo que transcurre entre un evento A y uno B. Por otro lado, también, estas técnicas pueden ayudar a analizar los aceleradores o retardantes del tiempo que tarda el evento de estudio a ocurrir. Por último, la ventaja analítica en la ciencia política y en la política comparada, en comparación con cualquier otra metodología, es que el análisis de supervivencia puede hacer estudios incluyendo datos con censura, fenómenos a los cuales otras técnicas son insensibles.

Esta técnica es de suma importancia en este estudio porque permitirá analizar la supervivencia de un régimen político en referencia al aumento y/o disminución de la inversión extranjera directa. El análisis de supervivencia está definido por el tiempo que transcurre hasta que ocurra un evento, mirándola como la variable dependiente o de respuesta (López, Martínez, \& Moreno, 2014). El análisis de supervivencia puede analizar la vida o muerte, en este caso, de un régimen político, como también puede medir el tiempo que puede transcurrir hasta que suceda un evento de interés, como también el tiempo de recurrencia o el tiempo que puede durar la eficacia de cualquier intervención, entre otras. Por esto, la supervivencia puede ser una medida de tiempo a una respuesta, muerte o desarrollo de algún evento (Fernández, 2001, pág. 1).

De acuerdo a este modelo, pueden existir varios factores que modifican la supervivencia de un individuo, en este caso, variables como la inversión extranjera directa, crecimiento económico, desempleo, entre otras. Existen tres requisitos básicos para poder hacer uso del análisis de supervivencia. La primera, precisar el origen o inicio del evento. Segundo, concretar la escala del tiempo. Y tercero, especificar el evento.

Dentro del análisis de supervivencia, lo que interesa es calcular la probabilidad de que un sujeto sobreviva hasta experimentar un cierto evento. De esta forma, de acuerdo a Klein y Moeschberger (2003) se obtiene dos funciones, la función de supervivencia y la función de Hazard. La función de supervivencia se la puede interpretar como la probabilidad de tener el evento dado que no se ha tenido hasta cierto tiempo de seguimiento. La función de Hazard es el riesgo instantáneo de tener un evento, dado que no se ha tenido hasta un tiempo t.

Existen ciertas diferencias con la función de superviviencia. La siguiente figura muestra lo mencionado. La gráfica de supervivencia siempre cae, nunca va de subida. Esto significa que a más tiempo que pasa más sujetos tendrán cierto evento, y por lo tanto la probabilidad de supervivencia 
disminuirá. La probabilidad al inicio es siempre $100 \%$, ya que todos los sujetos no han tenido el evento todavía. Conforme pasa el tiempo, los sujetos irán viviendo el evento y la probabilidad irá bajando. La función de supervivencia puede tomar muchas formas. Puede ser una pendiente en caída, puede ser una pendiente que primero tiene una meseta y luego tiene una caída, o una gráfica con una meseta corta y una caída brusca, todo depende de cómo se comporte el evento que se esté observando. En la siguiente figura en la línea semi-cortada (_-_.), un ejemplo podría ser que a los 5 años aproximadamente el $70 \%$ de los sujetos ha tenido el evento. En otras palabras, el 30\% de los sujetos de estudio han sobrevivido al evento de estudio.

$$
S(t)=P(T>t)=\int_{t}^{\infty} f(u) d u
$$

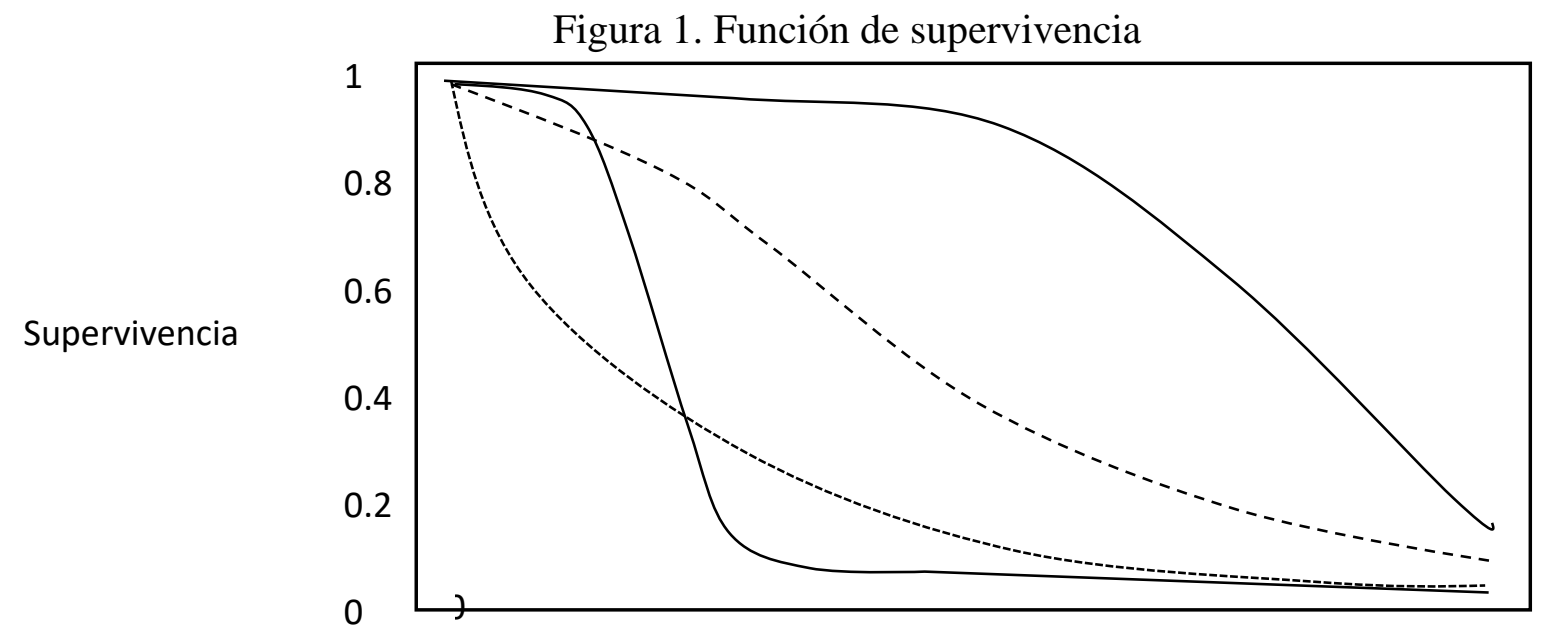

Tiempo

Fuente: Creación del autor. Datos provienen de: Cleves, Gouldy y Gutierrez, 2004; Arribalzaga, 2007.

La función Hazard, por otro lado, mide el riesgo instantáneo. A diferencia de la función de supervivencia, la función Harzard podría variar bastante en el tiempo. La interpretación de esta función es condicional, es decir, el riesgo instantáneo de tener el evento dado que no se ha tenido hasta cierto tiempo t, un tiempo t que será definido por el investigador (Cleves, Gould y Gutierrez, 2004; Arribalzaga, 2007; Klein y Moeschberger, 2003).

$h(t)=\lim _{\Delta t \rightarrow 0} \frac{P[t<T \leq t+\Delta t \mid T>t]}{\Delta t}$

En relación a la gráfica, mientras que la función de supervivencia siempre va de bajada porque se realiza una evaluación en el tiempo, la función Harzard puede variar en el tiempo. No necesariamente tiene que ir de bajada, puede ir de subida, dado que está evaluando un riesgo instantáneo. Para estimar la supervivencia, se realizará a través del cálculo de tabla de Kaplan y Meier (Cleves, Gould, \& Gutierrez, 2004). Este método clásico calcula la supervivencia en el punto de tiempo donde ocurrió el evento. Finalmente, la regresión de Cox (Cleves, Gould, \& Gutierrez, 2004) permitirá evaluar la función de supervivencia en base al modelamiento de los Hazard. En este sentido, la función 
de supervivencia puede variar en base a otras variables, por lo cual la utilidad de la regresión es que se pueda incluir esas variables y mantenerlas constantes, para luego realizar una estimación más exacta de la función de supervivencia. La regresión de Cox es útil, ya que se puede usar todas las propiedades de regresión múltiple (control de otras variables).

\section{a. Endogeneidad entre variables y multicolinealidad}

Por una parte, la literatura muestra varios estudios donde se plantea que la estabilidad de un régimen político es la causa para el crecimiento económico (Mayhew, 1996; Guerra, 2001; Busse y Hefeker, 2005; Azzimonti y Sarte, 2007; Jense, 2008, entre otros). Sin embargo, también existen autores que expresan una relación inversa, es decir que el crecimiento económico es la causa para que exista estabilidad política (Moran, 2000; Chen, 2007, Londregan y Poole, 1990, Alesiana y Perotti, 1992; Lipset, 1959, 1979; Diamond, 1988; 1992; Almond, 1991; Przeworski, 1991, entre otros).

Este análisis plantea que la IED es un determinante de la estabilidad o inestabilidad de un régimen político, es decir, se analiza desde la perspectiva de la teoría de la modernización (Londregan y Poole, 1990; Boix y Stokes, 2003; Lipset, 1959), en la que el desarrollo económico si puede tener un impacto en la supervivencia de un régimen político democrático y/o autoritario. Extrapolando el mismo mecanismo, el aumento o disminución de la inversión extranjera directa puede tener un impacto causal sobre la probabilidad de transiciones de dictadura a democracias o viceversa.

En este sentido, surge el tema de endogeneidad, es decir, cuando en el modelo de regresión planteado, existe una correlación entre las variables independientes de estudio y el término de error. En este caso, endogeneidad por simultaneidad y por variable omitida (Cameron \& Trivedi, 2005). La endogeneidad por simultaneidad usualmente sucede cuando se encuentran en el mismo espacio de tiempo las variables que se analizan (Antonakis et al., 2014). Para ocuparnos del problema de endogeneidad de la variable independiente clave (inversión extranjera directa), se utilizó como instrumento la misma variable retrasada un año. En este sentido, los valores retrasados de las variables endógenas son tratados como variables exógenas (Kenned, 2003).

La endogeneidad por variable omitida ocurre cuando existe una variable omitida que puede afectar al mismo tiempo a las variables de estudio. Desde este punto de vista, surge en la literatura un debate sobre los modelos lineales y no lineales. Por un lado, Angrist y Pischke (2009) discuten sobre el efecto causal de un modelo lineal, pero mencionan, al mismo tiempo, que en los modelos no lineales no existe problema de endogeneidad, porque es un modelo no lineal por estimación de máxima verosimilitud, como por ejemplo la metodología análisis de supervivencia. Esto debido a que un modelo no lineal se utiliza para predecir, no para ver el efecto causal. Por otra parte, y después de una exhaustiva búsqueda en el estado del arte sobre endogeneidad, MacKenzie et al. (2014) resuelven este problema utilizando variables instrumentales de dos fases.

Esta investigación soluciona el problema de endogeneidad que existía entre régimen político e inversión extranjera directa mediante el uso de variables instrumentales de dos etapas. El procedimiento para la regresión de Cox a través de variables instrumentales de dos etapas comienza, primero, con una regresión con las dos variables endógenas. De este procedimiento surge un predictor. 
Este predictor se remplaza por la variable endógena y se la incluye en la segunda etapa, en la que se realiza nuevamente la regresión de Cox.

Por una parte, frente al problema de la posible multicolinealidad, el cual no sesga los estimadores pero los vuelve más ineficientes, procedí a realizar una correlación de todas las variables independientes incluidas en el modelo corregido. En este sentido, ninguno de los coeficientes de correlación superó el nivel de 0.5. En particular, las variables que presentaron mayor sospecha de estar correlacionadas (PIB per cápita en t e inversión extranjera directa en t-1) arrojan un valor de 0.09, con lo cual se descarta la existencia de multicolinealidad. Por otra parte, la utilidad de la metodología empleada en este estudio es que puede incluir variables independientes y mantenerlas constantes, para posteriormente efectuar una estimación más exacta de la función de supervivencia.

Tabla 1. Coeficiente de correlación IED t-1 con PIB per cápita

\begin{tabular}{lll}
\hline & FDI t-1 & GDP growth annual \\
\hline FDI t-1 & 1.0000 & \\
GDP growth annual & 0.0908 & 1.0000
\end{tabular}

Fuente: Creación del autor a través del programa estadístico Stata. Base de datos.

Tabla 2. Coeficiente de correlación entre todas las variables

\begin{tabular}{|c|c|c|c|c|c|c|}
\hline & FDI t-1 & $\begin{array}{l}\text { GDP growth } \\
\text { annual }\end{array}$ & $\begin{array}{l}\text { Wage and } \\
\text { salaried workers } \\
\text { total }\end{array}$ & $\begin{array}{l}\text { Unemploymen } \\
\text { t Total }\end{array}$ & $\begin{array}{l}\text { Inequality } \\
\text { Gini index }\end{array}$ & $\begin{array}{l}\text { Rule of Law } \\
\text { Percentile } \\
\text { Rank }\end{array}$ \\
\hline FDI t-1 & 1.0000 & & & & & \\
\hline GDP growth annual & -0.0074 & 1.0000 & & & & \\
\hline $\begin{array}{l}\text { Wage and salaried } \\
\text { workers total }\end{array}$ & 0.1128 & -0.1436 & 1.0000 & & & \\
\hline Unemployment Total & -0.0600 & 0.0621 & -0.0475 & 1.0000 & & \\
\hline Inequality Gini index & -0.1505 & -0.1001 & -0.4200 & 0.1840 & 1.0000 & \\
\hline Rule of Law Percentile & 0.1401 & -0.2012 & 0.4682 & -0.2901 & -0.4882 & 1.0000 \\
\hline Rank & & & & & & \\
\hline
\end{tabular}

Fuente: Creación del autor a través del programa estadístico Stata. Base de datos.

\section{IV.Datos y análisis de resultados}

Los datos para la variable dependiente se lo toman de la base de datos de Cheibub et al. (2010), quienes estudiaron 202 países, desde 1946 al 2008. Para las variables independientes, la fuente es la base de datos del Banco Mundial. Antes de analizar los resultados obtenidos, es menester mencionar que se ha procedido, primero, a la depuración de datos. Para esto, se procedió a unificar todas las bases 
de datos en una sola (estudio de n-grande - 192 países). Después de dicha depuración, la variable dependiente se lo dividió en dos. Es decir, la primera que consta en la base de datos como "Regime0Dem1Dict", en la que 0 representa todos los regímenes democráticos y 1 los regímenes dictatoriales. La segunda, que consta en la base de datos como "Regimen", es aquella que, de acuerdo al modelo de Cheibub et al. (2010), 0 corresponde a democracia parlamentaria, 1 democracia mixta (semipresidencial), 2 democracia presidencial, 3 dictadura civil, 4 dictadura militar, y 5 dictadura real. Esta variable se la puede ver en la base de datos como "est_reg", que representa la variable acumulada en el tiempo.

- Estadística descriptiva

Este epígrafe muestra la estadística descriptiva de la variable dependiente (figura 2). Desde 1969 al 2008 en promedio existieron más dictaduras que democracias como año-país.

Figura 2 Estadística descriptiva V.D. (regímenes democráticos y dictatoriales), 1969 al 2008

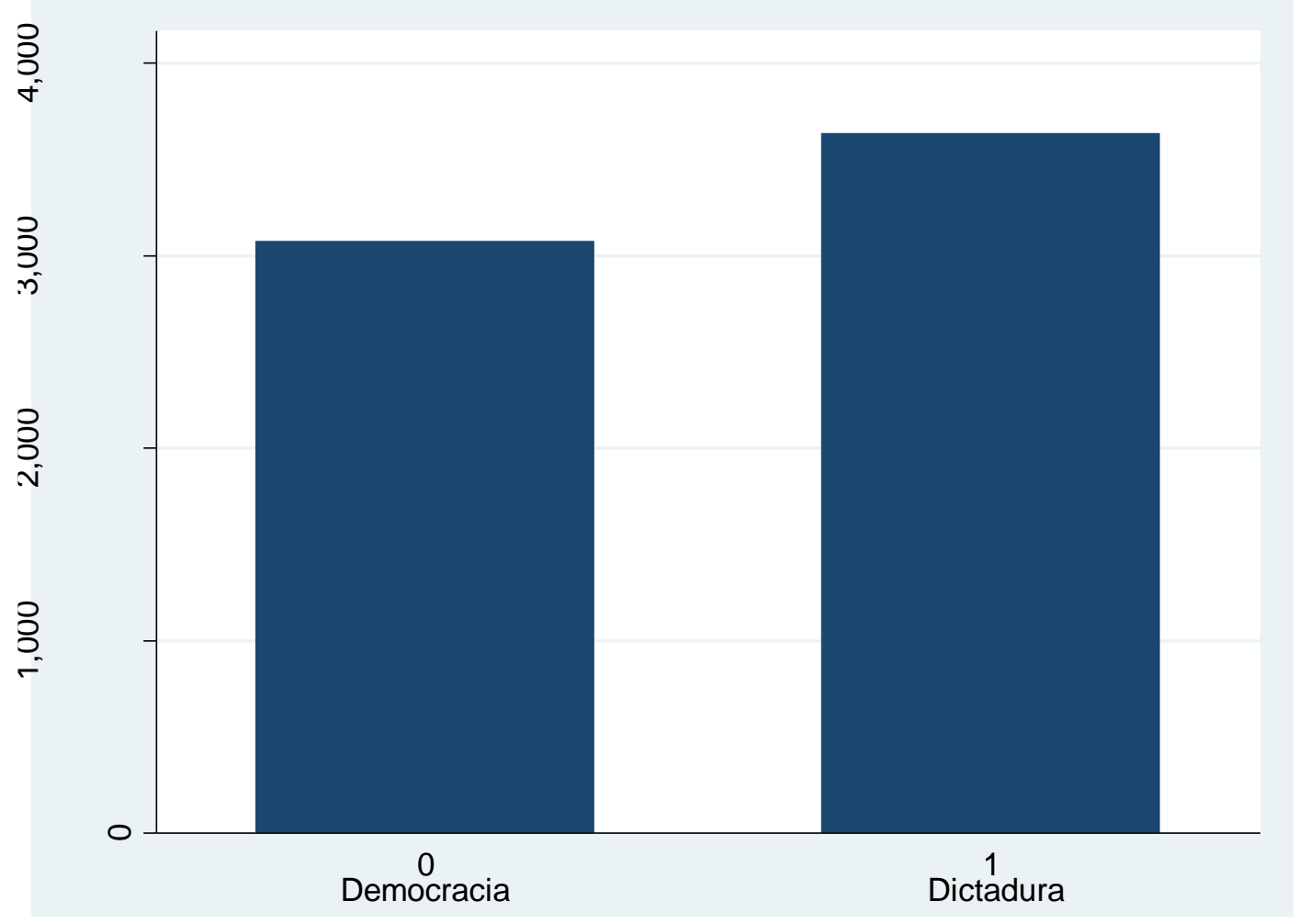

Fuente: Creación del autor a través del programa estadístico Stata. Base de datos.

Si bien la anterior gráfica muestra mayor cantidad de dictaduras que democracias, en la siguiente gráfica al desagregar la variable dependiente en los seis diferentes tipos de regímenes gubernamentales se tiene un mejor panorama de la cantidad de regímenes políticos por año-país desde 1969 al 2008. En este sentido, la dictadura real es la que registra mayor número en comparación con los demás regímenes políticos. No obstante, la democracia parlamentaria es el siguiente régimen político 
en cantidad de año-país, después sigue la dictadura militar, democracia presidencial, democracia semipresidencial o mixta y finalmente la dictadura real.

Figura 3 Estadística descriptiva V.D. (los seis diferentes tipos de regímenes políticos), 1969 al 2008

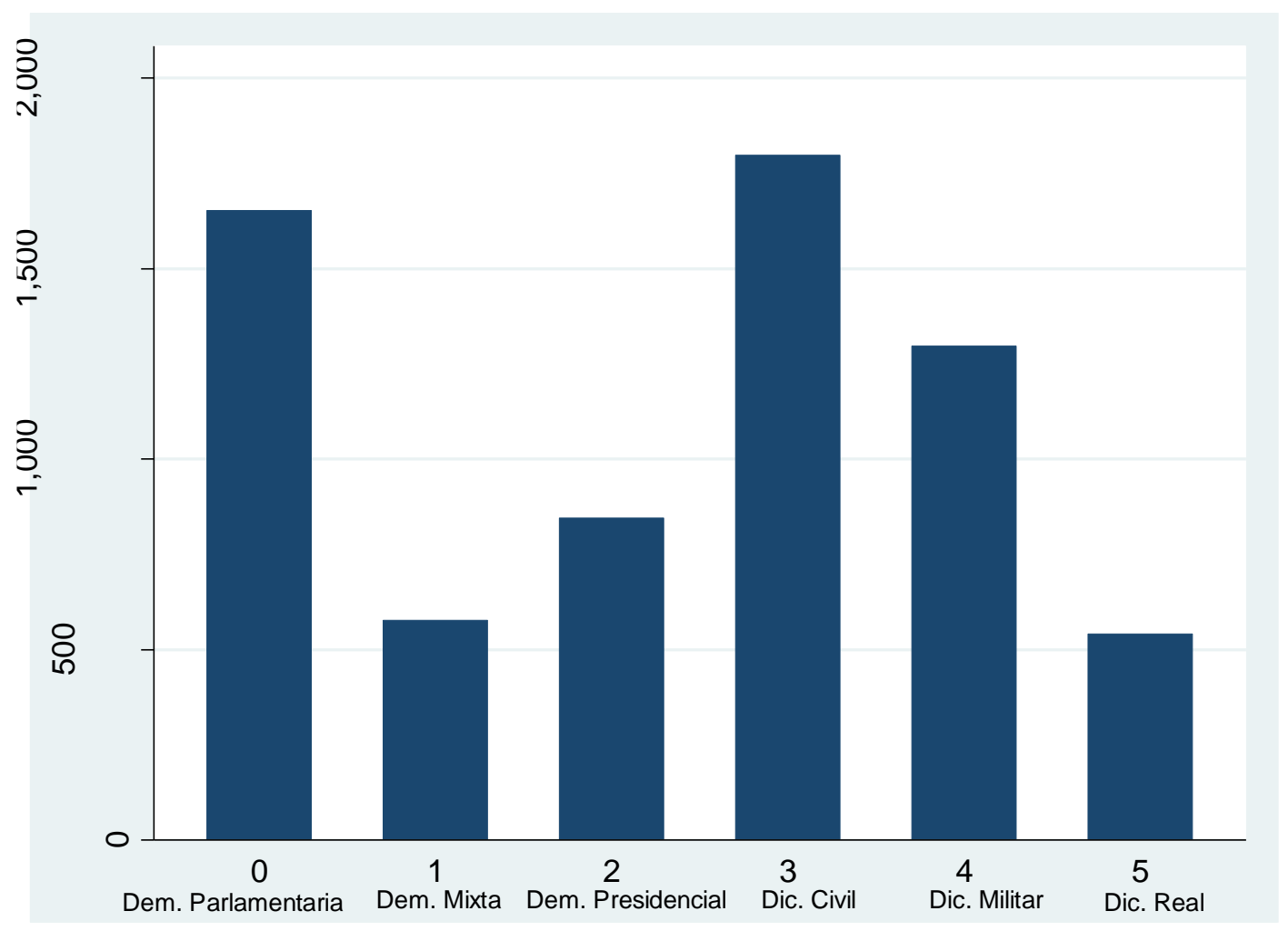

Fuente: Creación del autor a través del programa estadístico Stata. Base de datos. ${ }^{2}$

- Gráficas de Kaplan y Meier

Para estimar la supervivencia, se realizará a través del cálculo de tabla de Kaplan y Meier (Cleves, Gould, \& Gutierrez, 2004, págs. 93-105). Este método calcula la supervivencia en el punto de tiempo dónde ocurrió el evento. En este sentido, en la figura 4 podemos notar la gráfica de la función de supervivencia de Kaplan-Meier. En toda gráfica de estimación de supervivencia empieza en 1. A medida pasa el tiempo, la estimación de supervivencia disminuye. Esta gráfica da una clara idea de que, en promedio, los regímenes democráticos se mantuvieron más estables que las dictaduras. Empero los regímenes dictatoriales pierden estabilidad constantemente. Esto se lo puede ver más claramente cuando se realiza el estudio desagregando la variable dependiente en las seis subdivisiones (figura 5).

Figura 4. Kaplan-Meier, estimación de supervivencia de los regímenes democráticos y dictatoriales, 1969 al 2008

\footnotetext{
${ }^{2}$ Variable Dependiente: $0=$ democracia parlamentaria; $1=$ democracia mixta; $2=$ democracia presidencial; $3=$ dictadura civil; 4=dictadura militar; $5=$ dictadura real 


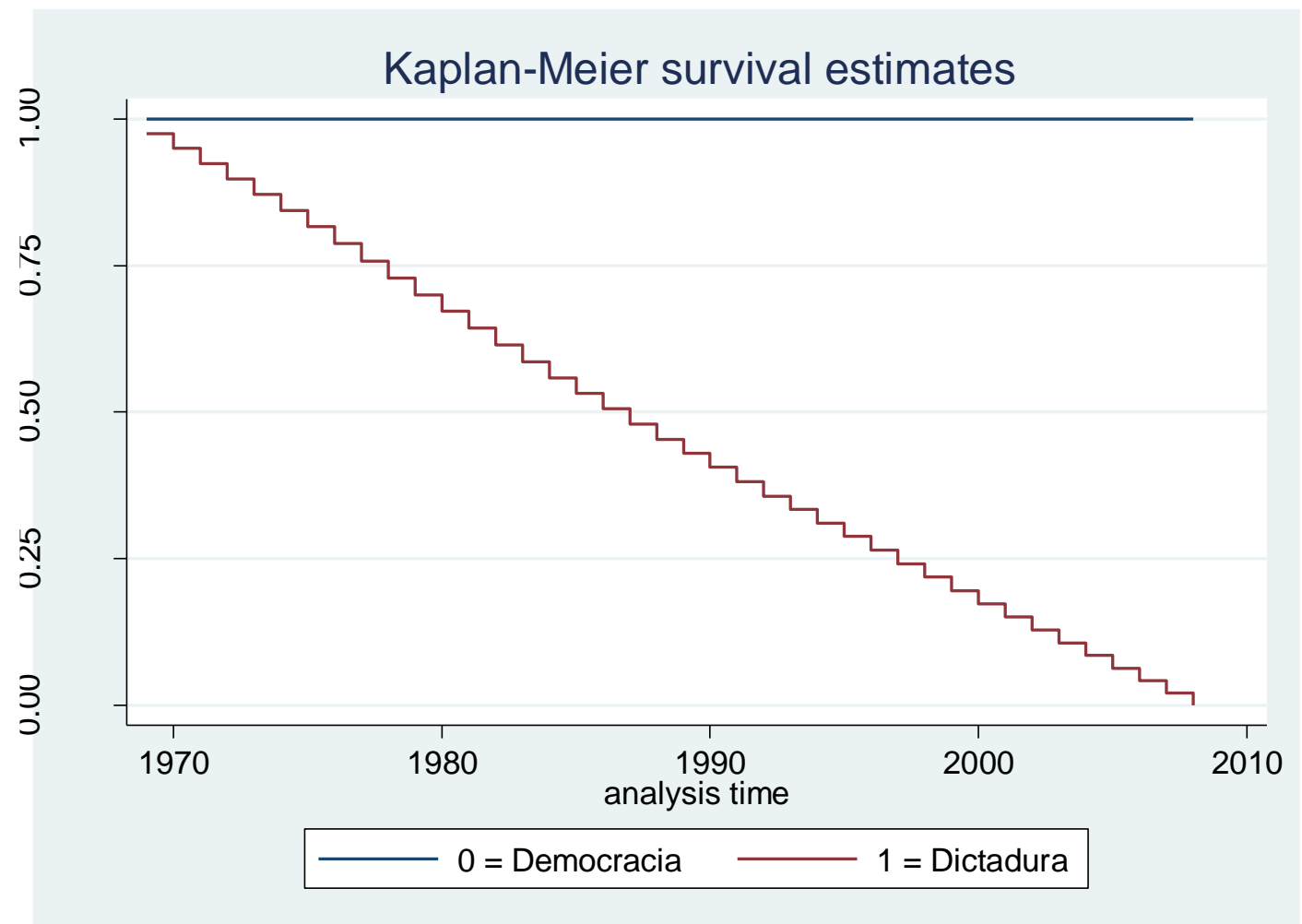

Fuente: Creación del autor a través del programa estadístico Stata. Base de datos.

De acuerdo a la figura 5, los regímenes democráticos parlamentarios se mantienen constantes (línea azul - 0). Los regímenes democráticos mixtos o semipresidenciales (línea rojo obscuro - 1) pierde estabilidad a velocidad lenta hasta aproximadamente el año 1991. Después, su estabilidad disminuye a una velocidad mayor. Lo mismo sucede con el régimen democrático presidencial (línea verde - 2). La diferencia es que su inestabilidad es mayor en comparación con el régimen político democrático mixto. Al analizar los diferentes tipos de dictaduras (dictadura civil, línea amarilla - 3; dictadura militar, línea celeste -4 ; dictadura real, línea rojo claro - 5), su estabilidad disminuye a mayor velocidad en comparación con los diferentes tipos de democracia. Sin embargo, su inestabilidad es de caída constante, hasta tal punto que en el 2008 llegan casi a juntarse todos los tipos de regímenes democracias mixtas y presidenciales. Esta gráfica muestra, por otro lado, que los regímenes políticos parlamentarios son los más constantes, en la que registra cero cambios de régimen político.

Figura 5. Kaplan-Meier, estimación de supervivencia de los seis diferentes tipos de regímenes políticos, 1969 al 2008 


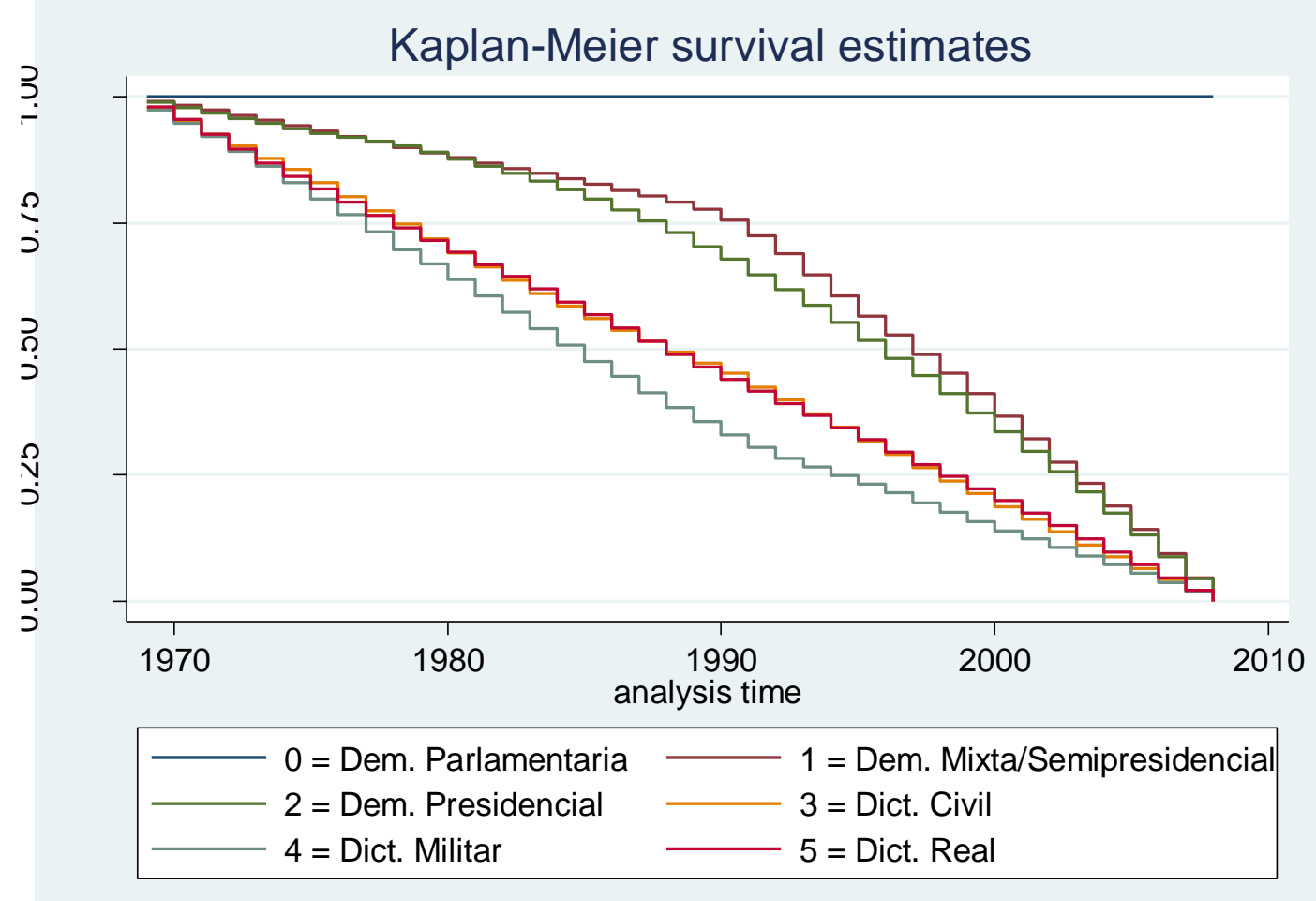

Fuente: Creación del autor a través del programa estadístico Stata. Base de datos.

Es importante, por otro lado, conocer la probabilidad que existe de tener el evento, es decir la probabilidad de que un régimen político pierda estabilidad. En la figura 6, los regímenes políticos dictatoriales (línea roja) tienen una mayor probabilidad de tener el evento, o mejor dicho de cambiar su tipo de régimen político a uno democrático. Los regímenes políticos democráticos en promedio, en cambio, registran poca probabilidad de tener el evento.

\section{Figura 6. Kaplan-Meier, probabilidad de tener el evento en los regímenes democráticos y} dictatoriales, 1969 al 2008 


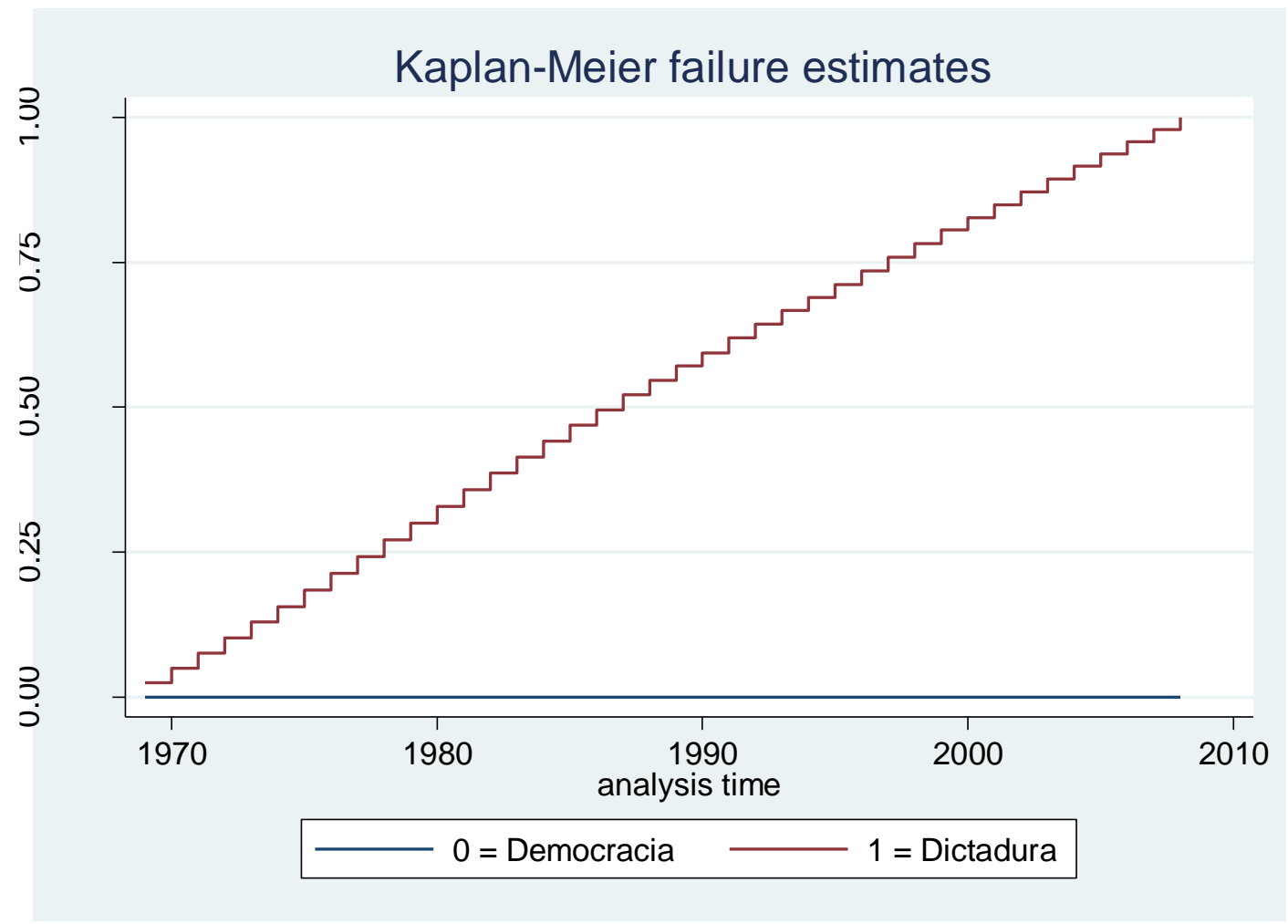

Fuente: Creación del autor a través del programa estadístico Stata. Base de datos.

En la figura 7 es parecida a la 6, empero desagregado en los diferentes tipos de régimen político. Esta gráfica muestra que la probabilidad de tener un cambio de régimen en los tres tipos de régimen político dictatorial aumenta. No obstante, al analizar los regímenes democráticos mixtos y semipresidenciales, su probabilidad también aumenta poco hasta el año 1990 aproximadamente. Posterior a esta fecha, su probabilidad de tener el evento incrementa a una velocidad mayor, casi llegando a las probabilidades de los regímenes dictatoriales. Esta gráfica comprueba la figura 5, en la que los regímenes políticos democráticos parlamentarios son los más estables en comparación con los otros cinco tipos de regímenes políticos.

Figura 7. Kaplan-Meier, probabilidad de tener el evento en los seis diferentes tipos de regímenes políticos, 1969 al 2008 


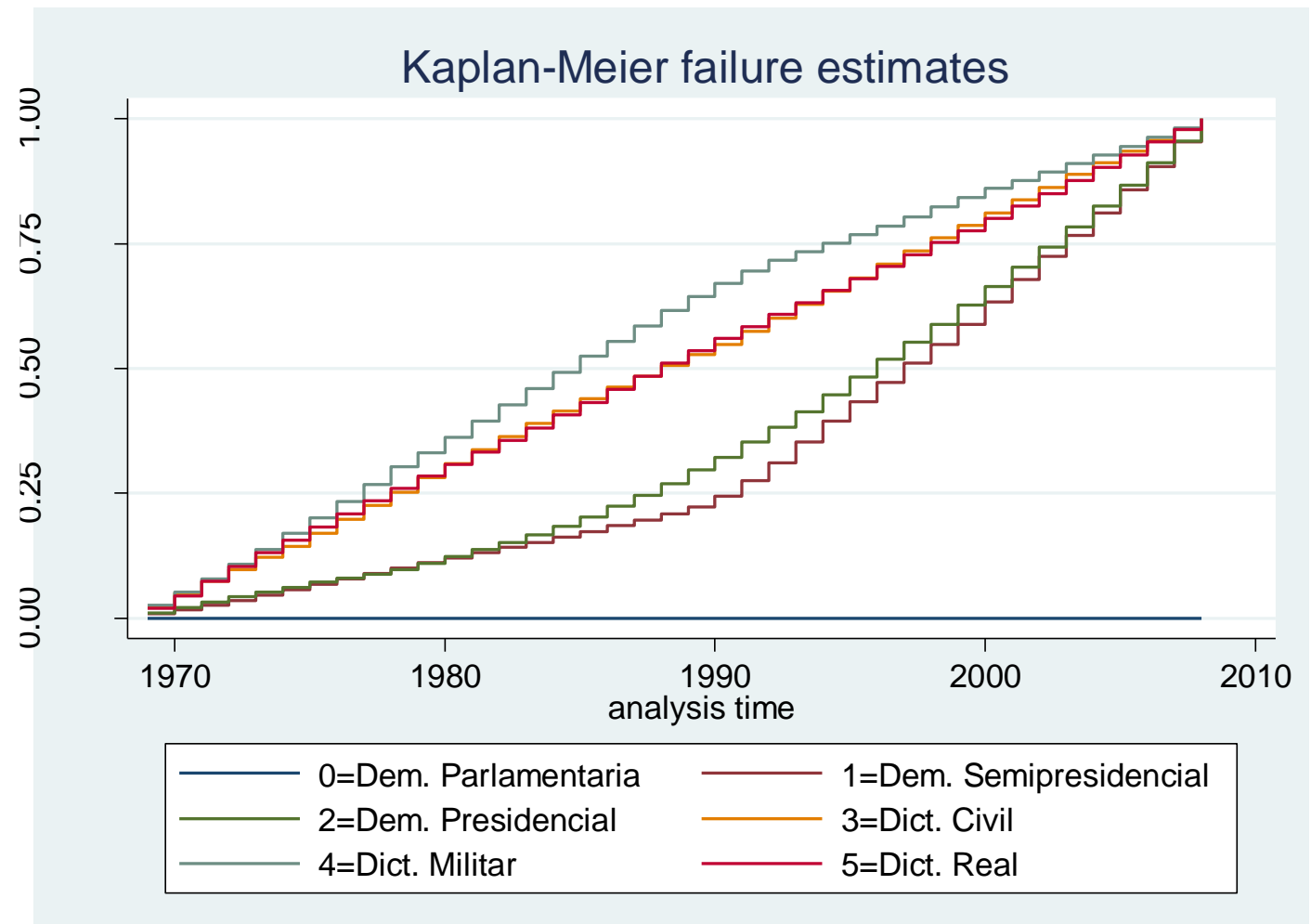

Fuente: Creación del autor a través del programa estadístico Stata. Base de datos.

- Regresión de Cox

La regresión de Cox (Cleves, Gould, \& Gutierrez, 2004, págs. 121-155) permite evaluar la función de supervivencia en base al modelamiento de los Hazard. En la tabla 3, se la puede interpretar directamente por medio de los coeficientes de riesgo (hazard ratio). Cuando el coeficiente es negativo (-) indica que tiene influencia en la probabilidad de supervivencia del régimen político. Cuando el coeficiente de riesgo es positivo (+) expresa una disminución en la probabilidad de supervivencia del régimen político. Sin embargo, en el coeficiente de Gini la interpretación es contraria, es decir, el coeficiente positivo indica que aumenta la probabilidad de supervivencia del régimen político. Esto ocurre cuándo el coeficiente de Gini tiende a cero (0) representa una equidad perfecta, mientras que un índice de cien (100) representa una inequidad perfecta.

En este sentido, en la siguiente tabla, la primera columna son las variables de estudio. La segunda columna muestra los resultados cuando mi variable dependiente está dividido dicotómicamente, es decir, cuando los regímenes políticos están divididos en democracias y dictaduras. La tercera columna son los resultados cuando se lo desagrega en los 6 diferentes tipos los regímenes políticos (democracia parlamentaria, democracia mixta, democracia presidencial, dictadura civil, dictadura militar y dictadura real). En la tercera columna, la regresión de Cox fue realizada mediante el procedimiento estratificado. Es decir, en la regresión se consideró los grupos existentes dentro los grupos de estudio. En este sentido, se trata de tener una estimación no sesgada y más eficiente.

Es importante mencionar que en los resultados de la regresión de Cox se contempla 356 períodos (spells) de las 6709 que se tiene en un principio. Esto se debe a que la base de datos registra 356 observaciones (observación: spells) con información completa entre todas las variables de estudio. En el resto de observaciones faltan datos en algunas variables, por lo que el programa estadístico Stata 
excluye estas observaciones en la regresión. Además, no se ha procedido a completar la información faltante con otras bases de datos, ya que al hacerlo se mezclaría las metodologías utilizadas en cada base de datos, lo cual generaría errores en la investigación.

Tabla 3. Regresión de Cox, de los regímenes democráticos y dictatoriales y de los seis diferentes tipos de regímenes políticos, 1969 al 2008 (outreg2)

\begin{tabular}{lcc}
\hline VARIABLES & Regimen0Dem1Dic & Regimen \\
$\mathrm{t}$ & $\mathrm{t}$ & $0.102 * * *$ \\
X1_h (FDI t-1) & $0.149 *$ & $(0.0334)$ \\
& $(0.0870)$ & -0.0205 \\
GDP growth annual & -0.0330 & $(0.0232)$ \\
& $(0.0265)$ & -0.00585 \\
Wage and salaried workers total & -0.00592 & $(0.00478)$ \\
& $(0.00479)$ & 0.0183 \\
Unemployment Total & 0.0245 & $(0.0149)$ \\
& $(0.0161)$ & $0.0174 * *$ \\
Inequality Gini index & $0.0175 * *$ & $(0.00750)$ \\
& $(0.00813)$ & $-0.00776 * *$ \\
Rule of Law Percentile Rank & $-0.00879 * *$ & $(0.00375)$ \\
& $(0.00393)$ & 356 \\
Observations & 356 & \\
\hline & &
\end{tabular}

Fuente: Creación del autor a través del programa estadístico Stata. Base de datos.

En la tabla 3, en la segunda columna, de un total de 356 períodos (observaciones: spells), cuando el régimen político se divide dicotómicamente, la disminución de la inversión extranjera directa (X1_h (FDI t-1)) disminuye la probabilidad de supervivencia de un régimen político (Regime0Dem1Dict). Es decir, el riesgo de cambio de un régimen político que tuvieron una disminución en la inversión extranjera directa es de $14.9 \%$ mayor de quienes si tuvieron un crecimiento de la inversión extranjera directa. Sin embargo, dicha influencia sigue siendo baja. Con relación a las variables de control, podemos comprobar lo que la literatura menciona de los mismos. Mientras aumenta el PIB per cápita (GDP growth annual), salario real promedio (Wage and salaried workers total), fortaleza del estado de derecho (Rule of Law Percentile Rank), y el empleo, o en otras palabras mientras disminuye el desempleo (Unemployment Total) aumenta la probabilidad de supervivencia de un régimen político. En relación al coeficiente de Gini (Inequality Gini index), a medida que aumenta este coeficiente (coeficiente positivo en esta tabla) aumenta la probabilidad de supervivencia de un régimen político. Esto debido a que el riesgo de cambio de un régimen político en la que aumenta el coeficiente positivo de Gini es de $1.75 \%$ menor de aquellos regímenes políticos en las que el coeficiente de Gini crece negativamente. 
Al analizar la tercera columna, es decir cuando la variable dependiente se divide en los seis diferentes tipos de regímenes políticos, la interpretación es casi la misma que la segunda columna. No obstante, la diferencia reside en que, de acuerdo a este modelo, las variables que, en menor o mayor medida, influyen en la variable dependiente son la inversión extranjera directa, el coeficiente de Gini y el estado de derecho. Es decir, el riesgo de cambio de un régimen político en la que tuvieron un aumento en el coeficiente positivo de Gini es de $1.74 \%$ menor de aquellos regímenes políticos que si tuvieron una reducción en el coeficiente de Gini. El riesgo de cambio de un régimen político en la que no tuvieron un aumento del estado de derecho es del $0.776 \%$ mayor de aquellos regímenes políticos que si tuvieron un aumento en el estado de derecho.

Al comparar la columna 2 y 3, se puede ver en la 3ra columna que el PIB per cápita, salario real promedio y el desempleo influyen en menor proporción en relación con la columna 2 a la probabilidad de supervivencia de un régimen político.

\section{Conclusiones}

El objetivo de esta investigación es determinar los efectos que tiene la inversión extranjera directa en la estabilidad de los regímenes políticos. Para ello, este análisis ha empezado con la construcción del estado del arte, el cual muestra que existen dos perspectivas de estudios: desde la ciencia económica y desde la ciencia política. Desde la ciencia económica, se ha encontrado una amplia gama de estudios en los cuales se toma al tipo de régimen político como variable independiente, y los índices económicos como variables dependientes. Es decir, se ha intentado ver el cómo la estabilidad de los regímenes políticos puede tener influencia en el desarrollo de las variables económicas. Por otro lado, desde la ciencia política, ve a la estabilidad del régimen político como la variable dependiente y como independientes las variables económicas, tal como se lo ha hecho desde la perspectiva de la teoría de la modernización.

Desde la ciencia política, hay estudios, como las de Mutascu (2009), Fielding (2002), Brady (2016) entre otros, que miran como el desarrollo económico, el costo de capital del usuario, salarios reales, las diferentes escalas de producción y los diferentes indicadores de incertidumbre económicos pueden tener influencia en la estabilidad de los regímenes políticos. Sin embargo, existe escasa literatura que estudie la influencia de la IED en la estabilidad de los regímenes gubernamentales. En este sentido se tiene las investigaciones de Moran (2000), Boix y Stokes (2003), Chen (2007) entre otros, que han analizado esta influencia en casos puntuales. No obstante, no se ha encontrado investigaciones globales de esta influencia. En consecuencia, este artículo llena ciertos vacíos en la literatura de la ciencia política a través de la presentación de resultados globales. Para esto, y de acuerdo a la disponibilidad de datos, se ha analizado 192 países desde 1969 al 2008.

Como se mencionó anteriormente, la literatura muestra estudios desde la ciencia económica y desde la ciencia política. Esta investigación plantea que la inversión extranjera directa es un determinante de la estabilidad de un régimen político. En virtud de ello, se realizó una búsqueda en el estado del arte sobre los problemas de endogeneidad que puede existir en esta investigación. Para resolver este problema, se procedió de dos formas. La primera, fue tomando los valores de la variable inversión extranjera directa de un año anterior a la variable régimen político, con el objetivo de evitar la endogeneidad por simultaneidad. Segundo, se resolvió el problema de la variable omitida mediante el uso de variables instrumentales de dos fases. De esta forma, se solucionó el problema de endogeneidad que existía entre las variables régimen político e inversión extranjera directa. Este artículo ha estudiado la estabilidad de los regímenes políticos desde la perspectiva de la Teoría de la Modernización 
(Londregan y Poole 1990; Boix y Stokes 2003; Lipset 1959); es decir, la IED sí tiene un impacto en la supervivencia de los regímenes políticos.

Con base en los resultados de las gráficas de Kaplan y Meier, y en las regresiones de Cox, se comprueba las dos hipótesis de esta investigación. La primera hipótesis hace referencia a que un aumento en la inversión extranjera directa aumenta la estabilidad de los regímenes políticos. Según los datos obtenidos, el aumento de la IED tiene un efecto positivo en la estabilidad de los regímenes políticos, sin embargo, dicho efecto es bajo. La IED, en general, tiene una influencia baja en la estabilidad de los regímenes políticos. No obstante, en países donde esta inversión presenta un significativo flujo económico, presenta un mayor impacto en la estabilidad del régimen político. Una futura agenda de investigación puede incluir estudios que presenten casos puntuales en los cuales la IED es un factor determinante para la estabilidad de los regímenes políticos.

Con relación a la segunda hipótesis, los resultados muestran que la IED tiene un impacto similar en todos los regímenes políticos; sin embargo, dado el hecho de que los regímenes democráticos son los que atraen mayores flujos de IED, la estabilidad de estos tipos de regímenes políticos muestra una mayor dependencia de la IED. En referencia a las investigaciones de Chen (2007), los gobiernos con alto crecimiento son las democracias fuertes: esta investigación muestra empíricamente que, en general, las democracias fuertes son las más importantes para atraer la IED. Al desagregar la variable dependiente, se puede observar que los regímenes políticos democráticos son aquellos que atraen mayor extranjera directa, y en particular, son los regímenes democráticos parlamentarios los que atraen mayores cantidades de IED. En este sentido, se confirma que el tipo de régimen político es importante para entender el flujo de la inversión extranjera directa.

Por otro lado, aunque en su conjunto, las dictaduras atraen menos IED que las democracias, también se puede visualizar con claridad que las dictaduras estables atraen más IED que las dictaduras inestables. Estos datos validan la segunda hipótesis, que los regímenes políticos democráticos atraen más IED que los regímenes dictatoriales.

En investigaciones como las de Przeworski y Limongi (1997), Robinson (2006) y Campos y Nugent (2001) se muestra que la relación causal entre la estabilidad de un régimen político y el desarrollo económico no son concluyentes. Esta investigación comprueba lo que la literatura ha mencionado sobre este tema; es decir, la inversión extranjera directa tiene una influencia positiva en la estabilidad de los regímenes políticos, sin embargo, esta influencia es de baja magnitud, por lo cual se puede decir que los resultados no son concluyentes.

Finalmente, futuras agendas de investigación pueden incluir dos puntos importantes. El primero, efectuar estudios de otras variables que puedan tener influencia en la estabilidad de los regímenes políticos. Segundo, examinar por qué la democracia parlamentaria ha sido el único régimen político que ha permanecido estable desde 1969 al 2008. Esta investigación provee de datos y conclusiones importantes, las cuales abren la puerta para considerar las agendas futuras de investigación propuestas. 


\section{Referencias}

Agiomirgianakis, G., Asteriou, D., \& Papathoma, K. (2003). The determinants of foreign direct. CITY, University of London. EST 1894(Report No. 03/06).

Ake, C. (1974, julio). Modernization and Political Instability: A Theoretical Exploration. World Politics 26, pp. 576-591.

Alesina, A., \& Perotti, R. (1992, Septiembre). The political economy of growth: a critical survey of the recent literature and some new results. NBER and CEPR(Discussion Paper Series No. 626), 1-47.

Alesina, A., Ozler, S., Roubini, N., \& Swagel, P. (1992, Septiembre). Political Instability and Economic Growth. NBER Working Paper Series(Working Paper No. 4173), 2-50.

Alliende, E. (1998). Para un concepto del Estado Social de Derecho.

Allison, P. (2014). Event history and survival analysis. Series: Quantitative Applications in the Social Sciences (2nd ed.). (H. Salmon, K. Coghill, \& B. Bauhaus, Eds.) Thousand Oaks, California, Estados Unidos: SAGE Publications, Inc.

Allison, P. D. (2010). Survival Analysis using SAS: A practical guide (Vol. 2). marzo, Estados Unidos: SAS Institute.

Almond, G. (1956, Agosto). Comparative Political Systems. The Journal of Politics, 18, No. 3., pp. 391-409.

Almond, G. (1991). Capitalism and Democracy. PS: Political Science \& Politics, 24(3), pp. 467-474.

Almond, G., \& Verba, S. (1992). La cultura política. In Ariel (Ed.), Diez textos básicos de Ciencia Política (pp. 170-201).

Angrist, J., \& Pischke, J.-S. (2009). Mostly Harmless Econometrics: An Empiricist's Companion. New Jersey, Estados Unidos: Princeton University Press. Retrieved from

https://www.researchgate.net/publication/51992844_Mostly_Harmless_Econometrics_An_Empiricist's_Companio $\mathrm{n}$

Antonakis, J., Bendaham, S., Jacquart, P., \& Lalive, R. (2014). Casuality and Endogeneity: Problems and solutions. The Oxford Handbook of Leadership and Organizations, 93-117. Retrieved from http://www.hec.unil.ch/jantonakis/Causality_and_endogeneity_final.pdf

Apter, D. (1965). The Politics of Modernization. Chicago, Estados Unidos: University of Chicago Press.

Arias, J. E., \& Zuluaga Borda, C. (28 de 07 de 2014). Financiación y ejecución de las actividades de investigación y desarrollo en Latinoamérica. (U. S. Tomás, Ed.) HALLAZGOS, págs. 311-328.

Arias, J. E., \& Zuluaga Borda, C. (28 de julio de 2014). Financiación y ejecución de las actividades de investigación y desarrollo en Latinoamérica. (U. S. Tomás, Ed.) HALLAZGOS, págs. 311-328.

Arribalzaga, E. (2007, febrero). Interpretación de las curvas de supervivencia. Revista Chilena de Cirugía, 59 n.1.

Asian Development Bank. (2004). Adian Development Outlook 2004 Update.

Asteriou, D., \& Price, S. (2000, diciembre 4). Political Instability and Economic Growth: UK Time Series Evidence.

Azzimonti, M., \& Sarte, P.-D. (2007). Barriers to foreign direct investment under political instability. Economic Quarterly, Vol. 93(No. 3), 287-315.

Banco Mundial. (n.d.). Banco de datos - Indicadores mundiales de buen gobierno. Retrieved julio 20, 2017, from http://databank.bancomundial.org/data/reports.aspx?source=indicadores-mundiales-de-buen-gobierno

Barbe, E. (1987, julio). El papel del realismo en las relaciones internacionales (La teoría de la política internacional de Hands. J. Morgenthau). Revista de Estudios Políticos (Nueva Epoca).

Bobbio, N. (1985). Capítulo I: El futuro de la democracia; Capítulo VII: ¿Gobierno de los hombres o gobierno de las leyes? In N. Bobbio, El futuro de la democracia (pp. 19-50; 195-221). Barcelona, España: Plaza \& Janes.

Boix, C., \& Stokes, S. (2003). Endogenous Democratization. World Politics, 55, pp. 517-549.

Bouoiyour, J. (2004). Foreign direct investment in Morocco. Munich Personal RePEc Achive (MPRA)(MPRA Paper No. $31457)$.

Brady, D. (2016, marzo 8). Globalization and Political Instability. The American Interest, 11, número 6.

Busse, M., \& Hefeker, C. (2005, Abril). Political Risk, Institutions and Foreign Direct Investment. Hamburg Institute of International Economics.

Bussmann, M., Scheuthle, H., \& Schneider, G. (2006). Trade Liberalization and Political Instability in Developing Countries. Trappl R. (eds) Programming for Peace, 2, 49-70.

Cajal, A. (n.d.). Lifeder Psicólogos. (Lifeder Psicólogos) Retrieved julio 20, 2017, from ¿Qué es la Inestabilidad Política?: https://www.lifeder.com/inestabilidad-politica/

Cameron, A., \& Trivedi, P. (2005). MIcroeconometrics. Methods and applications. Cambridge, Inglaterra: Cambridge University Press. Retrieved from http://www.centroportici.unina.it/centro/Cameron\&Trivedi.pdf

Sapienza: International Journal of Interdisciplinary Studies | Vol. 2 | n. 1 | jan - mar | 2021 | e-ISSN: 2675-9780 
Campante, F. R., Chor, D., \& Do, Q.-A. (2009). Instability and the Incentives for Corruption. Economics and Politics, Vol. 21(No. 1), 42-92.

Campos, N., \& Nugent, J. (2002). Who is afraid of political instability? Journal of Development Economics, 67(PII: S03043878Ž01.00181-X), 157-172.

Cheibub, J., Gandhi, J., \& Raymond Vreeland, J. (2010). Democracy and Dictatorship Revisited. Public Choice, 143, no.21, pp. 67-101.

Chen, L.-c. (2007). Development First, Democracy Later? Or Democracy First, Development Later? The Controversy over Development and Democracy.

Chen, L.-c., \& Feng, Y. (2000). Determinants of Economic Growth in China: Private enterprise, education, and openness. China Economic Review, 11, No. 1, 1-15.

Chudnosvsky, D., López, A., Laplane, M., Bittencourt, G., Masi, F., Domingo, R., . . Red MERCOSUR. (2005, 02). El book de inversión extranjera directa en el MERCOSUR. Red MERCOSUR.

Cleves, M., Gould, W., \& Gutierrez, R. (2004). An Introduction to Survival Analysis Using Stata. (Stata Corporation, Ed.) Texas, Estados Unidos: Stata Press Publication.

Collier, D. (1985). El nuevo autoritarísmo en América Latina. México: Fondo de Cultura Económica.

Collier, D., \& Levitsky, S. (1998). Democracia con adjetivos, innovación conceptual en la investigación comparativa. La Política, Número 4, pp. 137-160.

Correa López, G., \& González García, J. (2006, 06). La inversión extranjera: China como competidor y socio estratégico. Nueva Sociedad, pp. 114-127.

Correa López, G., \& González García, J. (2006, junio). La inversión extranjera: China como competidor y socio estratégico. Nueva Sociedad, pp. 114-127.

Cox, D. (1972). Regression Models and Life-Tables. Journal of the Royal Statistical Society. Series B (Methodological), 34(2), 187-220. Retrieved from https://www.jstor.org/stable/2985181?seq=1

Cukierman, A., Edwards, S., \& Tabellini, G. (1989, Diciembre). Seignorage and Political Instability. NBER Working Paper Series(Working Paper No. 3199), 1-54.

Databank - The World Bank. (n.d.). Foreign direct investment, net inflows (Bop, current US\$). Retrieved 09 18, 2017, from https://data.worldbank.org/indicator/BX.KLT.DINV.CD.WD?locations=EC\&view=chart

Databank - The World Bank. (n.d.). Foreign direct investment, net outflows (Bop, current US\$). Retrieved 09 18, 2017 , from https://data.worldbank.org/indicator/BM.KLT.DINV.CD.WD?locations=EC\&view=chart

Demirhan, E., \& Masca, M. (2008). Determinants Of Foreign Direct Investment Flows to Developing Countries: A CrossSectorial Analysis. Prague Economic Papers.

Diamond, L. (1990). Class, Ethnicity and Democracy in Nigeria: The Failure of The First Republic. The International Journal of African Historical Studies, 23.

Diamond, L. (1992, 03 1). Economic development and democracy reconsidered. American Behavioral Scientist, 35(4-5), pp. 450-499.

Diamond, L. (1992, marzo 1). Economic development and democracy reconsidered. American Behavioral Scientist, 35(45), pp. 450-499.

Diamond, L., \& Morlino, L. (n.d.). Introduction. In Assesing the Quality of Democracy. Baltimose, Estados Unidos: John Hopkins University Press.

Donolo, S. (2009, agosto 10). Triangulación: Procedimiento incorporado a nuevas metodologías de investigación. Revista unam.mx, 10, No. 8.

Easton, D. (1999). Enfoques sobre teoría política. (ISBN 959-518-025-X).

Edwards, S., \& Tabellini, G. (1991, Mayo). Political Instability, Political Weakness and Inflaction: and Empirical Analysis. NBER Working Papers Series(Working Paper No. 3721), 1-32.

Efron, B. (1987, febrero). Logistic Regression, Survival Analysis, and the Kaplan-Meier Curve. Department of Statistics, Stanford University, pp. 1-36.

Feng, Y. (1997, Julio). Democracy, political stability and economic growth. British Journal of Political Science, 27(3), 391418.

Fernández, P. (2001, abril 29). Análisis de superviviencia. Atención Primaria en la Red, pp. 1-14.

Ferrajoli, L. (1989). Derecho y razón. Teoría del garantismo penal. Prólogo de Norberto Bobbio. Madrid: Editorial Trotta. 
Fielding, D. (2002). Human rights, political instability and investment in south Africa: a note. Journal of Development Economics, 67, pp. 173-180.

Fjelde, H., \& Hegre, H. (2014). Political Corruption and Institutional Stability. Studies in Comparative International Development, Vol. 49(No. 3), 267-299.

Fleming, T., \& Harrington, D. (1993, marzo 1). Counting processes and survival analysis. Sage Journals, 2(1), pp. $113-114$.

Fuentelsaz, L., Gomez, J., \& Polo, Y. (2004, enero). Aplicación del análisis de superviviencia a la investigación en economía de la empresa. Cuadernos de economía y dirección de la empresa, No. 19, pp. 81-114.

Fuentes, G. C. (2009, 08). Naturaleza y tendencias de la ciencia, tecnología e innovación (CTI) en América Latina y el Caribe. Un análisis crítico al modelo institucional colombiano. Pensamiento \& Gestión, pp. 253-283.

Fuentes, G. C. (2009, agosto). Naturaleza y tendencias de la ciencia, tecnología e innovación (CTI) en América Latina y el Caribe. Un análisis crítico al modelo institucional colombiano. Pensamiento \& Gestión, pp. 253-283.

Gallardo, E., Molina, M., \& Cordero, R. (2016, junio). Aplicación del análisis de sobrevivencia al estudio del tiempo requerido para graduarse en educación superior: el caso de la universidad de Costa Rica. Scielo Uruguay, 9 No.1.

Gandhi, J. (2008). Political Institutions under Dictatorship. Cambridge: Cambridge University Press.

Garzón Valdes, E. (1992). El Concepto de Estabilidad de los Sistemas políticos. Distribuciones Fontamara, $165-168$.

González-Bustamante, B., \& Olivares , A. (2016). Cambios de gabinete y supervivencia de los ministros en Chile durante los gobiernos de la Concertación (1990-2010). Colombia Internacional, 81-208. doi:DOI: http://dx.doi.org/10.7440/colombiaint87.2016.04

Gozzi, G. (2007). Capítulo 5. Rechtsstaat and Individual Rights in German Constitutional History. In The Rule of Law (Vol. 80, pp. 237-259). Dordrecht, Holanda: Springer.

Guerra-Borges, A. (2001, Septiembre). Factores determinantes de la inversión extranjera: introducción a una teoría inexistente. Revista de Comercio Exterior, pp. 825-832.

Guo, Z., Kang, H., Cai, T., \& S. Small, D. (2018). Testing Endogeneity with High Dimensional Covariates. 1-69. Retrieved from https://arxiv.org/pdf/1609.06713.pdf

Gutiérrez, A. S. (2016, agosto). Análisis de supervivencia de proyectos de ley 2000-2016. Estado de la Nación, pp. 1-57.

Hannan, M., \& Carroll, G. (1979, mayo). Dynamics of Formal Political Structure: An Event-History Analysis. Stanford Sociology Technical Reports and Working Papers, 1-56. Retrieved from http://hdl.handle.net/1969.1/154808

Harrell, F. (2001). Cox Proportional Hazards Regression Model. In Regression Modeling Strategies. New York: Springer Series in Statistics.

Held, D. (2001). Capítulo 3: El desarrollo de la democracia liberal: a favor y en contra del Estado. In D. Held, Modelos de democracia (pp. 91-142). Madrid, España: Alianza.

Helmreich, J. (2016, abril 01). Regression Modeling Strategies with Applications to Linear Models, Logistic. Journal of Statistical Software, 70, pp. 1-3.

Huntington, S. (1968). Political Order in Changing Societies. New Haven and London, Yale University Press.

Huntington, S. (1968). Political Order in Changing Societies. New Haven: Yale University Press.

Huntington, S. (1998). La tercera ola de la democracia. UNAM, pp. 3-23.

Index Mundi. (n.d.). Índice de Gini. Retrieved 02 17, 2018, from Index Mundi:

https://www.indexmundi.com/es/datos/indicadores/SI.POV.GINI

International Monetary Fund. (n.d.). Balance of Payments Manual (Vol. 5ta Edición).

Jense, N. (2008, Octubre). Political risk, democratic institutions and foreign direct investment . The Journal of Politics, Vol. 70(No. 4).

Jimenez Barrera, Y. (2011, Noviembre). Teorías del desarrollo económico. Contribuciones a la Economía(ISSN 16968360).

Jong-A-Pin, R. (2008, Junio 5). Essays on political instability: Measurement, causes and consequences. Eschede, The Netherlands: PPI Publishers.

Kant, E. (1972). La paz perpetua.

Kant, I. (2005). Introducción a la teoría del derecho. Madrid, España: Ediciones Jurídicas y Sociales.

Kenned, P. (2003). A Guide to Econometrics (Vol. 1). Cambridge, Massachusetts, Estados Unidos: The MIT Press. Retrieved from https://econpapers.repec.org/bookchap/mtptitles/026261183x.htm 
Klein, J., \& Moeschberger, M. (2003). Survival Analysis: Techniques for censored and truncated data (segunda ed.). Estados Unidos.

Knutsen, C. H., \& Nygard, H. M. (2015, Julio). Institutional Characteristics and Regime Survival:Why Are SemiDemocracies Less Durable ThanAutocracies and Democracies? American Journal of Political Science, 59, No. 3, pp. 656-670.

Lapierre, J. (1976). En análisis de los sitemas políticos. (J. De Benavent, Trans.) España: EDICIONS 62.

Lawrence, C. (2007). Regime Stability and Presidential Government The Legacy of Authoritarian Rule, 1951-90. (T. U.

Mississippi, Ed.) Journal of the Ukrainian National Institute for Strategic Studies, Vol. 5.

Lin, D. (2014). Survival Analysis. Chapel Hill, Carolina del Norte, Estados Unidos: Department oof Biostatistivs, University of North Carolina.

Linz, J. (1998). Los problemas de las democracias y la diversidad de democracia. La democracia en sus textos, pp. $225-266$.

Linz, J. (2000). Totalitarian and Authoritarian Regimes. Lynne Rienner Publishers, p. 343.

Linz, J., \& Stepan, A. (1996). Hacia la consolidación democrática. Número 2, Paidós, pp. 29-49.

Lipset, S. (1959). Some Social Requisites of Democracy: Economic Development and Political Legitimacy. The American Political Science Review, 53, No. 1, pp. 69-105.

Lipset, S. (1979). Some social requisites of democracy: Economic development an political legitimacy. The American Political Science Review, 53, No. 1, pp. 69-105.

Lipset, S. (1996). Repensando los requisitos sociales de la democracia. Número 2, Paidós, pp. 51-87.

Loja, L., \& Torres, O. (2013). La inversión extranjera directa en el Ecuador durante el período 1970-2011: Análisis de su incidencia en el crecimiento económico. Cuencia, Ecuador: Universidad de Cuenca.

Londregan, J., \& Poole, K. (1990, Junio). Poverty, the coup trap, and the seizure of executive power. World Politics JSTOR, 42, No. 2, 151-183.

Londregan, J., \& Poole, K. (1990). Poverty, the Coup Trap, and the Seizure of Executive Power. World Politics, 42, pp. 151-183.

López, J., Martínez, R., \& Moreno, L. (2014). Capítulo 34: Análisis de supervivencia. In J. García, J. López, F. Ponce, Y. Ramírez, L. Pérez, A. Bernal, \& S. d. McGRAW-HILL INTERAMERICANA EDITORES (Ed.), Metodología de la investigación, bioestadística y bioinformática en ciencias médicas y de la salud (2nd ed.). México: Hospital General de México.

MacKenzie, T., Tosteson, T., Morden, N., Stukel, T., \& O'malley, J. (2014, diciembre 12). Using instrumental variables to estimate a Cox's proportional hazards regression subject to additive confounding. Health Serv Outcomes Res Methodol, 54-68. doi:10.1007/s10742-014-0117-x

Marshall, M., \& Jaggers, K. (2007, Octubre 24). Political Regime Characteristics and Transitions, 1800-2006. Center for Systemic Peace.

Marshall, M., \& Jaggers, K. (2009). Political Regime Characteristics and Transitions, 1800-2007. Center for Systemic Peace.

Martínez, C. (2015). Presidential survival in South America: Rethinking the role of democracy. International Political Science Review, 38, 40-55. doi:https://doi.org/10.1177/0192512115604904

Mathieson, D., \& Rojas-Suarez, L. (1992, June). Liberalization of the Capital Account: Experiences and Issues. IMF Working Paper - International Monetary Fund, Ocassional Papers, núm. 103.

Mayhew, A. (1996). Foreign investment, economic growth, and theories of value: evidence from economic history. In A. John, \& A. Scaperlanda, The Institutional Economics of the International Economy. Boston: Kluwer Academi Publishers.

Meyer, E. (1995). Jesús Reyes Heroles y su concepción social del derecho. pp. 357-274.

Mohl, R. (1832-1834). La ciencia de política alemana en conformidad con los principios de los Estados de derecho (en alemán Die deutsche Polizei-wissenschaft nach den Grundsätzen des Rechtsstaates). Hathi Trust. Digital Library, $V 1-V 3$.

Molina, J., \& Levine, D. (2007). La calidad de la democracia en América Latina: una visión comparada. Revista América Latina Hoy, Número 45, pp. 17-46.

Moran, T. (2000). Inversión extranjera directa y desarrollo (1 ed.). (L. Aguilar, \& E. Fernández, Eds.) San Rafael, México: Oxford University Press México. 
Mortimore, M., Vergara, S., \& Katz, J. (2001, 08). La competitividad internacional y el desarrollo nacional: implicancias para la política de inversión extranjera directa (IED) en América Latina. CEPAL SERIE Desarrollo productivo, No. 107.

Mortimore, M., Vergara, S., \& Katz, J. (2001, agosto). La competitividad internacional y el desarrollo nacional: implicancias para la política de inversión extranjera directa (IED) en América Latina. CEPAL SERIE Desarrollo productivo, No. 107.

Mutascu, M. (2009). Political regime durability, development and governance: the Romania's case. Stiinte Economice.

Mutascu, M. (2009). Political regime durability, development and governance: the Romania's case. Stiinte Economice. Retrieved from http://anale.feaa.uaic.ro/anale/resurse/34_E03_Mutascu.pdf

Naranjo N., A. (2017, octubre). Estabilidad del régimen ecuatoriano e inversión extranjera directa. FLACSO Ecuador, Política Compara, Quito.

Naranjo Navas, A. D. (2017, septiembre 27). Trabajo practico. Entrevistas en profundidad.

Naranjo, A. (2017, septiembre 27). Trabajo práctico. Entrevistas en profundidad. FLACSO Ecuador, pp. 1-22.

Needler, M. (1971). Politics and Society in Mexico. University of New Mexico Press, p. 143.

Novales, A. (2010). Análisis de Regresión. Madrid, España: Departamento de Economİa Cunatitativa, Universidad Complutense.

Nun, J. (2002). Democracia ¿Gobierno del pueblo o de los políticos? Fondo de Cultura Económica, pp. 9-22.

Obando Camino, I. (2004). La teoría de la congruencia revisitada - Harry Eckstein y su aporte a la teoría democrática. Estudios Constitucionales, 2, núm. 1, pp. 13-35.

O'Donnell. (1979). Modernization and Bureaucratic Authoritarianismo: Studies in South American Politics. Berkeley: Institute of International Studies.

O'Donnell, G. (2002). Las poliarquías y la (in)efectividad de la ley en América Latina. In J. Méndez, G. O`Donnell, \& P. Pinheiro, La (in)efectividad de la ley y la exclusión en América Latina (pp. 305-366).

O'Donnell, G. (2010). Capítulo I: El régimen democrático (o democracia política) y la ciudadanía como agencia. In G. O'Donnell, Democracia, agencia y estado (pp. 23-45). Buenos Aires, Argentina: Prometeo.

Organización Mundial del Comercio. (1996). "El Comercio y la inversión extranjera directa" Nuevo Informe de la OMC. Organización Mundial del Comercio.

Orwell, G. (1940, Marzo 11). Inside the Whale and Other Essays. Retrieved from http://orwell.ru/library/reviews/dickens/english/e_chd

Parada Corrales, J. (2004). Realismo crítico en investigación en ciencias sociales: una introducción. Investigación y Desarrollo, Vol 12 No. 2. indb, pp. 396-429.

Pinzón, E. (2016, octubre 20). Dealing With and Understanding Endogeneity. StataCorp LP, 1-59. Retrieved from https://www.stata.com/meeting/spain16/slides/pinzon-spain16.pdf

PNUD. (2004). Capítulo: Indicadores de desarrollo de la democracia. In La democracia en América Latina (pp. 73-135). Nueva York, Estados Unidos: PNUD.

Przeworski, A. (1992, Mayo). Democracy and the Market: Political and Economic Reforms in Eastern Europe and Latin America. Bulletin of Latin American Research, 11, No. 2.

Przeworski, A. (1995). Capítulo I: Democracia. In A. Przeworski, Democracia y mercado (pp. 14-85). Cambridge University.

Przeworski, A. (2011, Octubre). La mecánica de la inestabilidad política en Latinoamérica. Revista Jurídica de la Universidad de Palermo.

Przeworski, A., \& Limongi, F. (1993). Political regimes and economic growth. Journal of Economic Perspectives, 7, No. 3, pp. 51-69.

Przeworski, A., \& Limongi, F. (1997, Enero). Modernization: Theories and Facts. World Politics, 49, No. 2, pp. 155-183.

Ramírez Robledo, C. E., \& Laura, F. (2006, 03). Apuntes de inversión extranjera directa: definiciones, tipología y casos de aplicación colombianos. Apuntes de Economía, No. 8.

Ramírez Robledo, C. E., \& Laura, F. (2006, marzo). Apuntes de inversión extranjera directa: definiciones, tipología y casos de aplicación colombianos. Apuntes de Economía, No. 8.

Ramos Morales, L. L. (2012). Método comparado: precisiones y características. Revista de Ciencia Política.

Raz, J. (1985). La autoridad del derecho, Ensayos sobre derecho y moral, (traducción de Rolando Tamayo y Salmorán). México: Universidad Nacional Autónoma de México (UNAM), Instituto de Investigaciones Jurídicas. 
Reyes, G. (2009). Teorías de desarrollo económico y social: articulación con el planteamiento de desarrollo humano. Tendencias, X No. 1, pp. 117-142.

Robinson, J. (2006, Febrero 22). ECONOMIC DEVELOPMENT AND DEMOCRACY. Annual Review of Political Science.

Rodríguez, G. (2017). Generalized Linear Models. (P. University, Editor, \& Princeton University) Retrieved abril 02, 2018, from Data Princeton University: http://data.princeton.edu/wws509/notes/c7s1.html

Rodríguez, N. (2012, 12). El riesgo país en la inversión estranjera directa: concepto y modalidades de riesgo (The country risk in foreign direct investment: concept and categories of risks). Revistas Cientificas Complutenses (Universidad Complutense de Madrid).

Rodríguez, N. (2012, diciembre). El riesgo país en la inversión estranjera directa: concepto y modalidades de riesgo (The country risk in foreign direct investment: concept and categories of risks). Revistas Científicas Complutenses (Universidad Complutense de Madrid).

Sachs, J., \& Warner, A. (1995). Economic reform and the process of global integratio. Brookings Papers on Economic Activity, 1-118.

Salinas Esteban, F., \& Jalil Barney, M. (2014, 04). Herramientas teórico conceptuales para el análisis de la toma de decisiones en comités de Economía Pública. Análisis Político, $N^{\circ}$ 80, pp. 165-190.

Salinas Esteban, F., \& Jalil Barney, M. (2014, abril). Herramientas teórico conceptuales para el análisis de la toma de decisiones en comités de Economía Pública. Análisis Político, $N^{\circ}$ 80, pp. 165-190.

Salinas, M. (2008, junio 1). Modelos de Regresión VI. Análisis de Supervivencia (Regression Model VI. Survival Analysis). Ciencia \& Trabajo(No. 28), pp. 75-78.

Sanders, D. (1981). Patterns of political instability. Palgrave Macmillan.

Santabárbara, J. (2016). Manual de análisis de supervivencia: curvas de supervivencia y regresión de Cox. Zaragoza, España: Prensas de la Universidad de Zaragoza.

Saravia, A. (2015, Otoño). Political Regime Stability and Economic Freedom. Cato Journal, Vol. 35(No. 3), 581-602.

Schmitter, P., \& Lyn Karl, T. (n.d.). Qué es y qué no es la democracia. El surgimiento global de la democracia, pp. 37-49.

Sestelo, M. (2017, Noviembre). A short course on Survival Analysis applied to the Financial Industry (Vol. v1.2). Madrid, España: BBVA Data \& Analytics. Retrieved from https://bookdown.org/sestelo/sa_financial/

Shatz, H. (2001, Marzo). Expanding Foreign Direct Investment in the Andean Countries. CID Working Paper, No. 64.

Soliz Zapata, J. (2015). La inversión extranjera directa en el Ecuador y su incidencia en la economía, período 2008-2013. Guayaquil, Guayas, Ecuador: Universidad de Guayaquil.

Spence, M., \& Brady, D. (2016, marzo 23). La economía en épocas de inestabilidad política. World Economic Forum.

StataCorp LLC. (2017). Survival analysis. (StataCorp LLC) Retrieved 1 2, 2018, from Stata Data Analysis and Statistical Software: https://www.stata.com/manuals/stsurvivalanalysis.pdf

Strnag, T. (2014, diciembre 2). 100 Quotations from Dr. Albert Einstein. SCRIBD.

Subgerencia Cultural del Banco de la República. (2015). Régimen autoritario. Retrieved Junio 11, 2017, from http://www.banrepcultural.org/blaavirtual/ayudadetareas/politica/regimen_autoritario

Tomaselli, I., \& García, J. (2000). Informe de la subregión del Cono Sur. FAO - Food and Agriculture Organization of the United Nations. Roma, Italia: FAO.

United Nations Publications. (2016). World Investment Report 2016. Investor Nationality: Policy Challenges. United Nations. Geneva: United Nations.

Vergara, S. (08 de 2001). El mercado vitivinícola mundial y el flujo de inversión extranjera a Chile. Serie Desarrollo Productivo, No. 102.

Vergara, S. (agosto de 2001). El mercado vitivinícola mundial y el flujo de inversión extranjera a Chile. Serie Desarrollo Productivo, No. 102.

Vial, J. (2001, Junio). Inversión Extranjera en los Países Andinos. CID Working Paper. Center for International Development at Harvard Univeristy.

White, S. (2006). The Cambridge Companion to Habermas. Nueva York: Cambridge University Press.

Wooldridge, J. M. (2010). Econometric Analysis of Cross Section and Panel Data. Cambridge, Massachusetts, Inglaterra: The MIT Press.

Yacuzzi, E. (2005, Agosto). El estudio de caso como metodología de investigación: teoría, mecanismos causales, validación. EconPapers(No 296, CEMA Working papers: Sedie Documentos de Trabajo). 